\title{
Brain cancer-activated microglia: a potential role for sphingolipids
}

\author{
Daniele Bottai ${ }^{a}$, Raffaella Adami ${ }^{\text {, }}$ Rita Paronia, Riccardo Ghidoni ${ }^{*}$ \\ a Department of Health Sciences, University of Milan, Milan, Italy
}

\begin{abstract}
: an immune intervention.

\section{INTRODUCTION}

Since their discovery, which saw the first use of the term "Sphingolipids" (SLs) [1, 2], interest in this important class of lipids has increased steadily. The complete description of highly heterogeneous SLs molecular structures [3], and the enzyme activities of the complex metabolic pathways in which they are involved, however, was achieved only recently, after advanced techniques became available ("Lipid Maps" at http:// www.lipidmaps.org) [4].

We now know that the role of SLs ranges from that of structural lipids of the cellular membrane to their involvement, with other lipids (cholesterol, triglycerides), in the fluidity regulation, and in the cell-cell interaction and recognition. Nowadays, many of the components of this complex family of molecules are widely recognized as "active lipids", i.e., true mediators able to respond to external stimuli and in turn to regulate specific downstream metabolic pathways and effectors on specific targets [4]. The questions that remain open and needs further study pertain to the relationship between the mechanisms tuning and regulating all the pathways involved in SLs metabolism and the cell requirements and conditions, their role in pathophysiology and their use in translational medicine. The role of SLs in cancer biology and in immune and inflammatory functions is one of the most intriguing features of these "bioactive lipids": this is what prompted us to survey the literature in search of a role played by microglia activation in brain cancer.
\end{abstract}

Almost no neurological disease exists without microglial activation. Microglia exert a pivotal role in the maintenance of the central nervous system and its response to external and internal insults. Microglia have traditionally been classified as, in the healthy central nervous system, "resting", with branched morphology system and, as a response to disease, "activated", with amoeboid morphology; as a response to diseases but this distinction is now outmoded. The most devastating disease that hits the brain is cancer, in particular glioblastoma. Glioblastoma multiforme is the most aggressive glioma with high invasiveness and little chance of being surgically removed. During tumor onset, many brain alterations are present and microglia have a major role because the tumor itself changes microglia from the pro-inflammatory state to the anti-inflammatory and protects the tumor from

What are the determinants of these changes in the behavior of the microglia? In this review, we survey and discuss the role of sphingolipids in microglia activation in the progression of brain tumors, with a particular focus on glioblastoma.

Keywords: Ceramide, inflammation, ganglioside, brain tumor, microglia-tumor interaction, microglia activation.

\section{SLs}

\subsection{Structure of SLs}

SLs are a large, heterogeneous class of amino alcohol molecules deriving from the common eighteen carbon amino-alcohol backbone of sphinganine or its unsaturated analog sphingosine, (Sph) (2S, 3R, 4e)-2-aminooctade-4ene-1,3-diol). Sph, which is the simplest SL and the most

\footnotetext{
*Address correspondence to this author at the Department of Health sciences, University of Milan, Milan, Italy; Tel: +39 0250323250; Email: riccardo.ghidoni@unimi.it
}

common form in mammals Fig. (1), undergoes a range of biochemical modifications that give rise to many different and more complex structures. The glycosphingolipids (GSLs) class, which is the most representative, includes several species differing by the number and the order of sugar residues attached to their head-groups. Fig. (1).

There are many features by which variants of the sphingoid backbone present in nature are recognized, for instance the length of the alkyl chain, the number and/or position of unsaturation, the presence of hydroxyl groups. $\mathrm{N}$-acylation on the $\mathrm{C} 2$-amino group yields ceramide (Cer), the central hub of SL metabolism, Fig. (1), with fatty
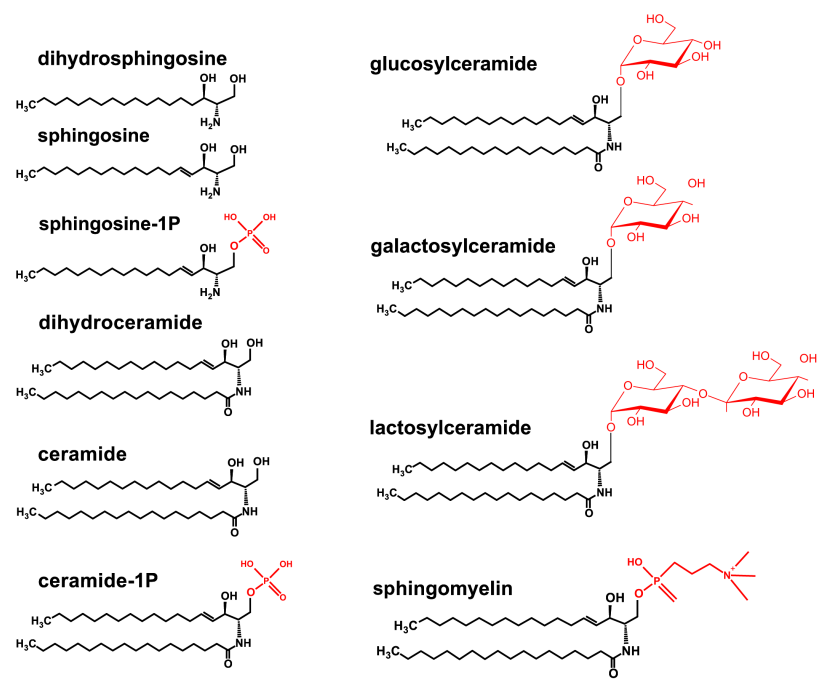

Fig. (1). The structure of major SLs and GSLs. The sphingoid base is in the D-erythro $(2 \mathrm{~S}, 3 \mathrm{R})$ conformation and $\mathrm{d}=18: 1$. In the figure the fatty acyl chain linked to the amino group of sphingosine has 18 carbon atoms but it can vary from 14 to 26 , generating the heterogeneous family of SLs.

chains of 14 to 26 carbon atoms saturated or monounsaturated. These molecules are the backbone for more complex SLs which are formed by attachment of the 
head groups at the C1-hydroxyl group. For instance, the addition of a phosphate residue gives rise to ceramide-1phosphate (Cer1P), while the addition of a phosphocholine residue produces sphingomyelins (SMs, the most common sphingolipid of the cell membrane in mammals), and the addition of one or more carbohydrates yields the complex family of GSLs Figs (1-2). GSLs are typified on the basis of their carbohydrate composition, the most important classes being: i) neutral GSLs that contain glucose, galactose, lactose, fucose, $\mathrm{N}$-acetylglucosamine (GlcNAc), $\mathrm{N}$-acetylgalactosamine (GalNAc), ii) acid GSLs that contain a phosphate or sulfate group bound to neutral or charged sugar residues Figs (1-2), iii) gangliosides typified by the presence of one or more sialic acid residues in the carbohydrate moiety, and, finally iv) basic and amphoteric GSLs [4-7] Figs (1-2).

\subsection{SL metabolism}

Two major synthetic pathways concur in the synthesis

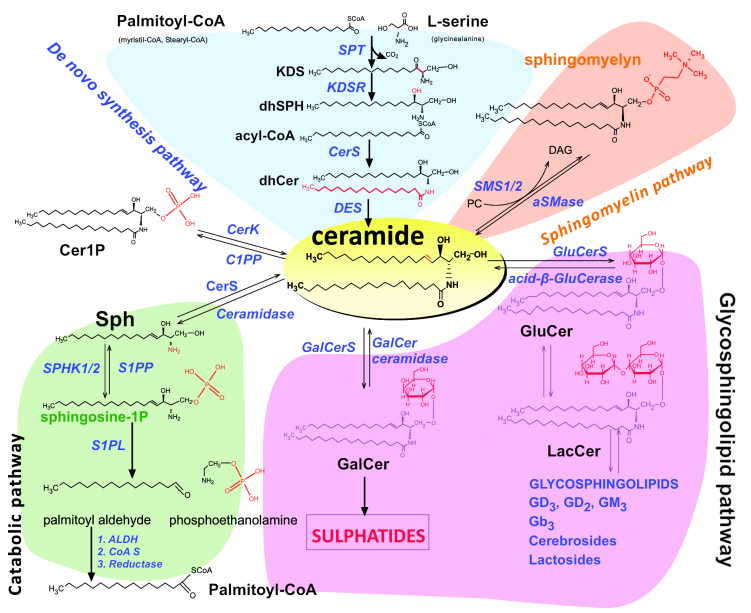

Fig. (2). . Sphingolipid metabolism. "De novo", "Salvage", "Sphingomyelin pathway", and "catabolic" pathways" can be are indicated. Abbreviations: Coenzyme A: CoA; serine palmitoyltransferase: SPT; 3-keto-Dihydrosphingosine: KDS; 3-ketodihydrosphingosine reductase: KDSR; dihydrosphingosine: dhSPH; dihydro ceramide: dhCer; (dihydro)ceramide synthase: CerS; (dihydro) ceramide desaturase: DES; DAG: diacylglycerol; phosphatidylcholine: PC; sphingomyelin synthase: SMS; sphingomyelinase: aSMase; ceramide kinase: CerK; ceramide-1P Cer-1P; ceramide-1P: phosphatase: C1PP, sphingosine: Sph; glucosylceramide synthase: GluCer; acid- $\beta$-glucosylceramidase: acid- $\beta$-GluCerase; galactosylceramide: GalCer; galactosylceramide synthase: GalCerS; galactosylceramide galactosylceramide: GalCer; ceramidase: GalCer ceramidase; glucosylceramide: GluCer; lactosylceramide: LacCer; ganglioside M3: GM3; ganglioside D3: GD3; ganglioside D2: GD2; globotriaosylceramide 3: Gb3; sphingosine kinase: SPHK; sphingosine-1-phosphate phosphatase: S1PP; sphingosine-1-phosphate lyase: S1PL; CoA synthase: CoAS; aldehyde dehydrogenase: ALDH.

of SLs moiety Fig. (2): de novo and salvage pathways [8, 9]. The enzyme serine palmitoyltransferase (SPT) catalyzes the first step of the de novo biosynthesis of SLs in the endoplasmic reticulum (ER). 3-ketodihydrosphingosine reductase (KDSR) catalyzes the synthesis of dihydrosphingosine (dhSPH) Fig.s (1-2), which then can be either acylated by ceramide synthase (CerS) and desaturated by ceramide desaturase (DES), producing the Cer family. Ceramidase gives rise to Sph which in turn can be phosphorylated, with the production of Sphingosine-1-phosphate (S1P) by sphingosine kinase 1 and 2 (SPHK1; SPHK2). The salvage pathway [10] and the hydrolysis of SM (sphingomyelin pathway) are two alternative pathways for Cer synthesis. SM is produced via the transfer of phosphocholine from phosphatidylcholine to Cer by one two enzymes: sphingomyelin synthase 1 or sphingomyelin synthase 2 (SMS1-2). The first seems responsible for de novo synthesis, whereas the second is likely involved in the re-synthesis from SM catabolism. The attachment of a polar head to Cer, forming SM, occurs in the Golgi where Cer is transported by the Cer transfer protein. A vesicular transport from ER to Golgi instead allows galactosylceramide (GalCer) synthesis which permits the further synthesis (in the trans Golgi) of GSLs [11].

All the production of GSLs originates from two Cer products: glucosylceramide (GluCer) and GalCer. The first generates lactosylceramide (LacCer), which is the precursor of asialo-, asialoganglio-, globo-, neolacto-, and lacto- GSLs [12] Fig. (2). SLs are degraded into lysosomes via the action of acid sphingomyelinases (aSMase) and glycosidases forming Cers. SMs are also degraded also at the plasma membrane level by the action of the acid or the neutral SMase, depending on the side of the membrane on which the reaction takes place and then Cer is converted to Sph. At this point, all the Sph produced can carry out its intracellular functions or undergo a change by SPHK1 or 2 phosphorylation to generate sphingosine-1-phosphate (S1P), which can act as a second messenger or as an extracellular ligand, or be metabolized [11]. Two enzymes can transform S1P: sphingosine-1phosphate phosphatases (S1PP), which regenerates Sph sphingosine-1-phosphate lyase (S1PL), which catalyzes the irreversible degradation of S1P to phosphoethanolamine and palmitoyl aldehyde [13] Fig. (2).

\subsection{SL functions}

SLs, as fundamental elements of lipid rafts, structurally constitute and functionally influence the organization of cellular membranes and the dynamics and the secretion of exosomes (vesicles implicated in cell-cell signaling and communication). They are, moreover, actively involved as intracellular messengers in the regulation of cell functions. For example, it has been reported that inhibition of SMase2 enhances exosome secretion from neurons and improves the clearance of neurotoxic amyloid- $\beta$ by microglial cells, thus opening new therapeutic perspectives in Alzheimer disease by modulating the metabolism of SLs [14].

SLs heterogeneity is also reflected in the heterogeneity of their functions, to such an extent that relative species equilibrium is decisive in directing cell fate, towards death or survival pathways. The most representative example is the dualism between Cer, a death effector, and S1P, a cell proliferation and survival promoter $[15,16]$. However, an 
increasing number of scientific studies have now shown a neurotoxic effect of S1P [17] and a cytotoxic effect in pancreas $\beta$-cells [18]. A large number of extracellular signals or stimuli elevates intracellular Cer (heat shock, ionizing radiation, oxidative stress, tumor necrosis factor (TNF)- $\alpha$, nitric oxide (NO), etc.) [19]. Cer acts as a typical second messenger, binding to plasma membrane proteins and regulating their activity, or physically interacting with the cell or mitochondria membranes, inducing the fusion of GSL and cholesterol-containing rafts into large macrodomains of proteins associated with apoptotic signaling mechanisms $[20,21]$. As a consequence, Cer can induce cell death by apoptosis [22] necroptosis [23], autophagy [24] and ER stress [25], depending on cell and/ or tissue type, subcellular localization of Cer, and/or the availability of downstream targets of Cer [26].

By contrast, S1P can directly promote a number of intracellular activities such as cytoskeletal rearrangement, cell migration, angiogenesis [27], vascular maturation, embryonic development of the heart, immunity and lymphocyte trafficking. S1P can also bind, in an autocrine fashion, to receptors (S1PRs), triggering inositol triphosphate (IP3)-independent calcium mobilization and DNA synthesis [26]. Sph seems to have the same properties as Cer, while Cer1P shares similar functions with S1P [28]. The fate of the cell-towards survival or death-depends on a delicate equilibrium between different pro- or anti-apoptotic SLs, the relative amounts of which are controlled by the expression or activity of enzymes that either produce or degrade them.

\subsection{Subcellular compartmentalization of SL} metabolism

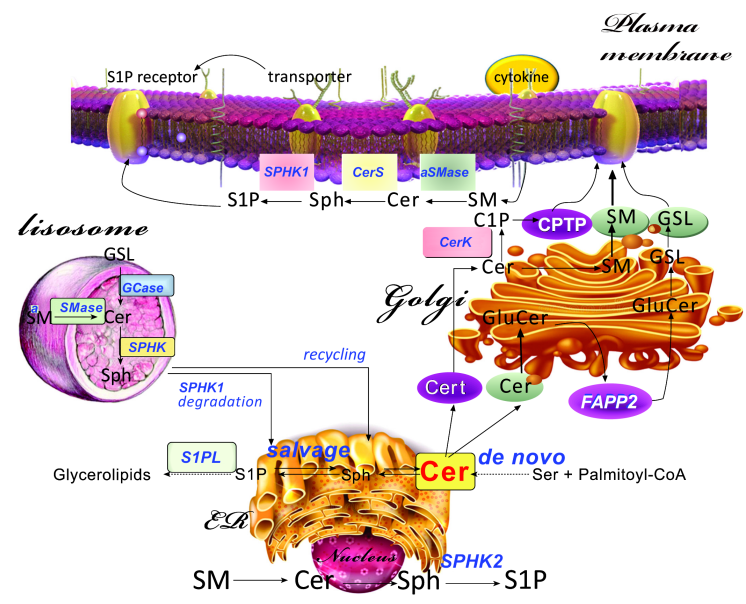

Fig. (3) Subcellular compartmentalization of sphingolipid metabolism. Abbreviations: Sphingosine-1-phosphate: S1P; sphingosine: Sph; ceramide: Cer; sphingomyeline: SM; sphingosine kinase 1: SPHK1; Ceramide Synthase: CerS; sphingomyelinase: aSMase; ceramide kinase: CerK, ceramide-1-phosphate transfer protein: CPTP; glucosylceramide: GluCer; glycosphingolipid: GSL; Ceramide transfer protein: CERT; four-phosphate adaptor protein 2 : FAPP2; glucocerebrosidase: GCase; sphingosine-1-phosphate lyase: S1PL; endoplasmic reticulum: ER.
Depending on their chemical structure, SLs exert their action on the biological membranes or leave their site of generation and move into cytoplasmic and extracellular spaces, exploiting specific transport mechanisms. For this reason, the roles of many SLs are closely connected with the specific subcellular localization of their synthesis enzymes Fig. (3).

In particular, their mobility is based on the number of hydrophobic chains and on the charge at neutral $\mathrm{pH}$. Cer, with two aliphatic chains and neutral head-group, can flipflop membranes but is unable to move in the cytoplasm. Indeed, it reaches the Golgi apparatus through two different ways: by the action of transfer protein CERT, if SM generation is needed, or by using vesicular transport if GluCer, or, in general, GSLs, must be synthesized.

Vesicular transport is also involved in the mobilization of SMs and GSLs to the plasma membrane, from where they can be addressed to lysosomes for entering the endosomal salvage pathway. Due to their more hydrophilic nature, SLs with just one aliphatic chain are soluble in the cytosol and can freely move among intracellular membranes. Sph, not having any charge, can flip-flop membranes meanwhile, and its phosphorylated metabolite, S1P, is linked to specific transporters to pass through the lipid bilayer [4]. In particular, it has been demonstrated that S1P traffic is linked to ATP binding cassette (ABC) transporters; indeed, ABCC1 down regulation causes $\mathrm{S} 1 \mathrm{P}$ export reduction in human LAD2 mast cells $[29,30]$. SLs are highly present in the nucleus where they exert various functions. For instance, SM is

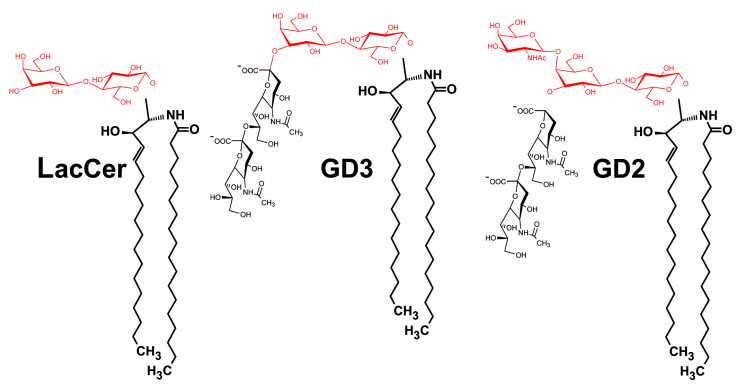

Fig. (4). Structure of Lactosyl ceramide precursor of the 0 series and of GD3 and GD2, gangliosides of the $b$ series involved in tumor aggression and poor prognosis. Abbreviations: lactosylceramide: LacCer; ganglioside D3: GD3; ganglioside D2: GD2.

located in the nuclear envelope where it has a role in DNA synthesis, chromatin assembly, and RNA stability, and some ganglioside are located in the nuclear envelope and have $\mathrm{Ca}^{2+}$ homeostatic and storage functions. Cer, Sph, and other Sph derivates are localized in the chromatin/ nucleosome portion. Ceramide has a role in apoptosis and protein degradation, and Sph acts on SF-1 gene transcript and host-pathogen interaction, whereas S1P and dhS1P are involved in histone acetylation and ROS generation. 
Finally, Cer1P has perinuclear localization and a role in cytosolic Phospholipase A2 (cPLA $)$ activation [31].

\subsection{Complex GSLs}

Complex GSLs, or gangliosides, are a subclass of GSLs containing one to five sialic acids linked to the sugar chain.

The head groups of gangliosides are negatively charged at $\mathrm{pH}$ 7, as sialic acid residues are deprotonated Fig. (4).

The gangliosides family contains more than 60 gangliosides, differing from each other mainly in the position and number of sialic acid residues [7].

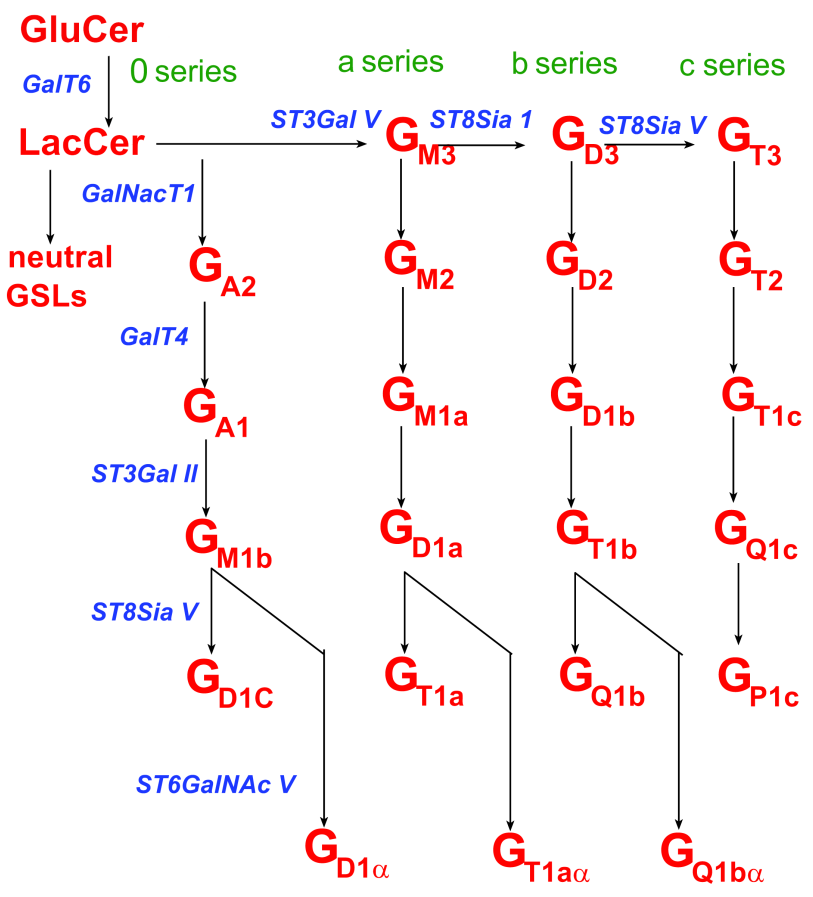

Fig. (5) Gangliosides are characterized by the number and positions of sialic acids that define their classification into $0, \mathrm{M}, \mathrm{D}, \mathrm{T}, \mathrm{Q}$, and $\mathrm{P}$ (zero to five sialic acids) and a, b, and c (one, two, or three sialic acids on internal Gal residue) series. In addition, the $\alpha$-series is defined by the presence of a sialic acid on the internal Galp-NAc residue. Abbreviations: glucosylceramide GluCer; lactosylceramide: LacCer; glycosphingolipids: GSLs; Polypeptide N- Acetylgalactosaminyltransferase 1: GalNAc-T1; polypeptide N-Acetylgalactosaminyltransferase 4: GalT4; ST3 $\beta$ Galactoside Alpha-2,3-Sialyltransferase 2: ST3Gal II; ST8 Alpha-NAcetyl-Neuraminide Alpha-2,8-Sialyltransferase 5: ST8Sia V; ST6 NAcetylgalactosaminide Alpha-2,6-Sialyltransferase 5: ST6GalNAc V; ST3 Beta-Galactoside Alpha-2,3-Sialyltransferase 5: ST3Gal V; ST8 Alpha-NAcetyl-Neuraminide Alpha-2,8-Sialyltransferase 1: ST8Sia I; ganglioside: G.

The biosynthesis of gangliosides starts with the transfer to the terminal non-reducing position of LacCer (Glu and Gal saccharides residues) of a sialic acid residue by specific sialyltransferases (ST3Gal V, ST8Sia I, and ST8Sia V) Fig. (4) [32]. LacCer, GM3, GD3, and GT3 are the precursors for 0 -, a-, b-, and c-series of gangliosides, and are characterized, respectively, by $0,1,2$ or 3 sialic acids on the Gal residue Fig. (5). Further addition of GalNAc to the Gal residue of these precursors gives the GA2, GM2, GD2 and GT2 gangliosides Figs. (4-5). A second Gal residue is then linked to the GalNAc of the chain in formation, followed by the sequential addition of two sialic acid residues (producing: GD1c, GT1a, GQ1b, and GP1c) Fig. (5). Complex GSLs are very abundant in the nervous tissue [33] and play an important regulatory role in neural stem cells (NSCs) [34].

\section{Microglia}

In 1919 Pío del Río-Hortega, a student of Cajal, developed the concept, introduced by his mentor a few years earlier, of the third element in the central nervous system (CNS). Whereas, neurons and astrocytes were previously considered the only elements present in the CNS, Cajal had introduced the glia, both "oligodendrocytes" and "microglia", to differentiate them clearly from astrocytes, in 1897 [35]. del Río-Hortega gave a first functional definition of the different morphologies of the microglia indicating that the rod-shaped cells were resting cells. On the other hand, the ameboid phenotype was present in a pathological brain [35] and despite his scientific dispute with Cajal del RíoHortega's contribution is pivotal for understanding the CNS organization.

Pío del Río-Hortega, also proposed that microglia cells are of mesodermal origin. Indeed, hematopoietic progenitors (as distinct from hematopoietic stem cells) are derived of the yolk-sac from primitive erythromyeloid precursors as early as 8 days post conception and enter the CNS in a single wave [36-39]. After leaving the yolk-sac, monoblast/ monocyte lineage precursors not only colonize the CNS but also reach the fetal liver (producing Kupffer cells), and epidermis (producing Langerhans cells). Microglia are defined as $\mathrm{CD} 11 \mathrm{~b}^{+} / \mathrm{CD} 45^{\text {low }}$ (or CD45int), whereas macrophages are identified as $\mathrm{CD}_{11} \mathrm{~b}^{+} / \mathrm{CD} 45^{\text {high }}$ [40].

The original understanding [or view] - dual activity based on branched morphology (in the healthy brain) and activated with amoeboid morphology (during a pathology) has now been laid aside. [39]. Nowadays, the function of microglia in the healthy and developing brain is understood to be much more complex and important than before, including that microglia are also present in the nonpathological and disease free CNS.

We can divide microglia activation into classical (M1) and alternative (M2) depending on the physio-pathological context. The M1 pro-inflammatory phenotype is the Toll-like receptor (TLR) 4 responder, whereas IL-4, 10 and 15 can stimulate M2 phenotype [41-43]. Microglia cells, however, have a high degree of plasticity, which makes us consider many sub-phenotypes of M2; at least 3: a, b, and c [41] that have different activators IL-4 and IL-13, TLR and IL-1R, and glucocorticoid respectively [44-46].

In the vertebrate CNS, development is accompanied by a consistent apoptosis that involves a major population of neurons and can affect $50 \%$ of the neurons in the peripheral nervous system or in some discrete areas of the CNS [47, 48].

Microglia have been found near apoptotic neurons during development, where they exert a double function: they remove the apoptotic debris $[49,50]$ (they are not the only cells performing this function), and they induce programmed cell death (especially in Purkinje cells) by releasing 
superoxide ion [51]. Microglia also promote also neuron survival by releasing trophic factors [52], and it is involved in the neurogenic areas such as sub-ventricular zone (SVZ) [53, 54]in the control of the size of the NSC pool [55]. During development, moreover, microglia are involved in the guidance of the developing vasculature and in the maturation and editing of neuronal circuits [39]. The different functions of the microglia are related to their level in the brain: their levels can vary by up to five-fold, and in the mouse brain they range from $5 \%$ of the total number of

cells

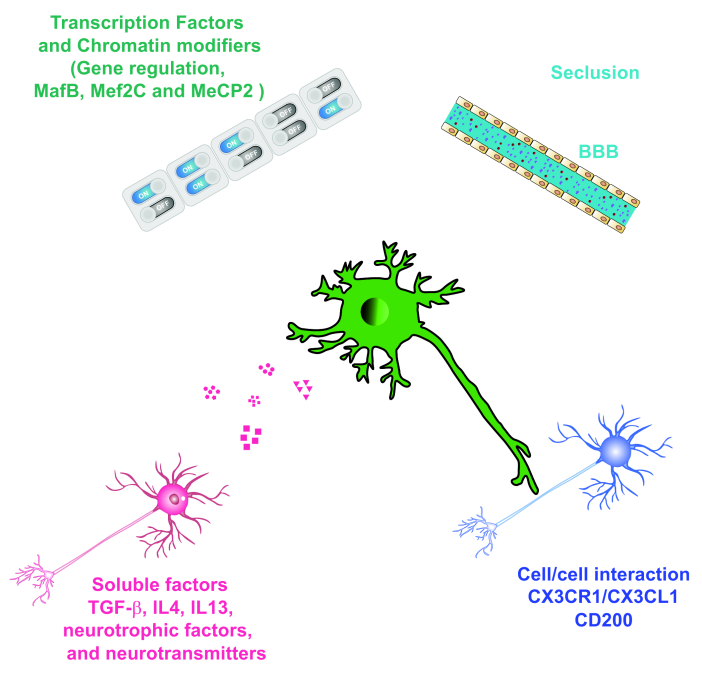

Fig. (6). Schematic representation of the different activity of the microglia in the CNS. The drawing describes the different check points (that control microglial immune activation while nurturing homeostatic functions) to which microglia undergo: cell-cell interaction, seclusion due to the blood brain barrier, control with soluble factors release from neuron or glia, alteration of gene expression. Abbreviations: blood brain barrier: BBB; Transforming growth factor- $\beta$ : TGF- $\beta$; interleukin 4 : IL-4; interleukin 13 : IL-13; MAF BZIP Transcription Factor B: MafB; Myocyte Enhancer Factor 2C: Mef2C; Methyl-CpG Binding Protein 2: MeCP2; C-X3-C Motif Chemokine Receptor 1:CX3CR1; C-X3-C Motif Chemokine Ligand 1: CX3CL1; CD200 Molecule: CD200.

in the cortex and $12 \%$ in the substantia nigra[56]. Microglia perform a regulatory activity at least in two neurogenic areas of the mouse brain such as SVZ [57] and hippocampus [58].

The present view of the role and action of microglia involves the presence of restraints of microglia activity, also indicated as checkpoints. These sorts of barriers include cellto-cell signals such as the adaptive response of the immune cell, intrinsic factors to the cells, the presence of anatomical barriers in the CNS, and the distinctive composition of the CNS microenvironment.

As mentioned earlier the activity during pathological condition is not regarded these days as an activation but rather as a shift in gene expression with signal-dependent transcription factors (SDTF). Consequently, different pathologies make the microglia adopt different phenotypes able to respond to the environment such as pathogenassociated molecular patterns, confrontations with tumors and apoptotic cells and contact with tissue debris, not necessarily protectively [59]. Seclusion from the blood circulation Fig. (6) determines a limited presence of defined phenotypes of leukocytes in the CNS under physiological conditions [60]. Transforming growth factor- $\beta$ (TGF- $\beta$ ) Fig. (6), which is secreted by astrocytes allows the appropriate immune-activated signature of the microglia [61]; interleukin 4 (IL-4) and IL-13, which are expressed at low levels in physiological conditions are up-regulated after pathological perturbation $[62,63]$. Neurotrophic factors Fig. (6) and neurotransmitters seem to be involved in microglia immunophenotype modulation; indeed, when neurotrophin-3 (NT3), brain-derived neurotrophic factor (BDNF), or nerve growth factor (NGF) are neutralized by antibodies there is an activation of the major histocompatibility complex-II, indicating an immune activation [64]. ATP, adrenaline, glutamate, $\gamma$-aminobutyric acid (GABA), dopamine, and adenosine can induce a response of microglia determining the appropriate immunophenotype related to the specific receptor activated [65].

Cell-cell interactions Fig. (6), especially with neighboring neurons, are now known to be another checkpoint for microglia with regard to their activation after the first in vitro evidence [66] where the fractalkine receptor (CX3CR1), which is ubiquitously expressed on microglia, were activated by its ligand (CX3CL1), produced by definite types of neurons [67]. The cell-cell interactions between microglia, neurons, oligodendrocytes, astrocytes and endothelial cells were recently found to be mediated by CD200 ligand and its receptor [68].

Another important mechanism of microglia immune activity is driven by transcription factors and the chromatin modifiers MafB, Mef2C and MeCP2 [69, 70] Fig. (6).

In this framework, we can postulate for a transcriptional control of microglia identity, with many various genes that can be activated by the factors mentioned above. Many lineage-determining transcription factors (LDTF) such as PU.1, which works as a main controller of the myeloid lineage [71], SALL1, a zinc finger transcriptional repressor which is important for neurogenesis and responsible of microglia morphology [72], and MAFB, which promotes an anti-inflammatory phenotype in macrophages [73] and has a role in establishing the physiological phenotype of the microglia. During disease, by contrast, other genes classified as SDTFs are activated in microglia by the environment. Some of them mediate inflammation: two examples are the NF-kB family, which plays key roles in inflammation and apoptosis [74] and is activated by ROS [75] and saturated fatty acids [76], and the AP-1 family, associated with immune activation, cell growth, differentiation and apoptosis [77], interferon regulatory factors (IRF). Within these latter, IRF8 was identified as a crucial regulator of microglia numbers [78] in mice and motility [79], the p53 tumor suppressor whose expression and activity increases in microglia in response to DNA damage, cellular stress, and oxidative stress [80]. The STAT family is activated in microglia by lipopolysaccharides (LPS, a big molecule made of lipid and polysaccharide that was found in the outer membrane of gram-negative bacteria) [81]. In other cases, the SDTFs exert an anti-inflammatory and tissue-supportive action on microglia: for instance Msh-like homeobox (MSX) which are implicated in brain development and neurogenesis 
and in the mouse are highly expressed in chemical amyotrophic lateral sclerosis (ALS) models [82], NURR1 which inhibits LPS-induced expression of pro-inflammatory cytokines [83], and estrogen receptors which exert an antiinflammatory effect [84].

Very interestingly SDTFs can regulate cholesterol and lipid metabolism; indeed, the beneficial effects of PPAR $\gamma$ agonists are produced by inhibiting pro-inflammatory activity and promoting the phagocytic activity of microglia [85]. The non-steroid nuclear receptors liver $\mathrm{X}$ receptors (LXRs) and retinoid X receptors (RXRs) play key roles in cholesterol homeostasis and inflammation and it has been suggested that they play a protective role by promoting the phagocytosis of amyloid- $\beta$ by microglia [86].

\section{Brain Tumor}

Tumors are the second most common cause of death, after cardio-circulatory disease, in the developed countries. Tumors arise when a few cells, or even just one, acquire(s) the capacity for uncontrolled and unlimited proliferation. This alteration is caused, in most of the cases, by genetic alterations such as abnormal DNA methylation, disorganized chromatin architecture, and histone modification patterns [87-89]. Many aggressive brain tumors in both adults and children, including ependymomas, glioblastomas and medulloblastoma present somatic mutations and structural alterations of either functional regulatory elements or epigenetic regulators [87, 88, 90-92].

The heterogeneity of brain cancer results both from the range of to their genetic compositions and from the prevailing local microenvironmental conditions: therefore metabolic factors and environmental factors, including the blood circulation, could have an impact on the mechanisms of the development of brain cancer [93, 94].

The global prevalence of primary malignant brain tumors (PMBTs) is near 11 persons per 100,000 per year [95]; however, the incidence of brain metastases, however, is 10 times more [96] and they mostly derive from breast cancer, melanoma, and lung cancer [97]. There are two theories that offer explanations for the origin of a tumor. The stochastic model asserts that cancer cells are very heterogeneous but essentially all of them could be a tumor founding cell, luckily this happens rarely, while in the hierarchical hypothesis -now widely supported [98] -only a small subpopulation of cancer cells can proliferate to any extent and sustain the growth of the clone. Cancer stem cells (CSCs) share plenty of properties with normal stem cells including self-renewal and the capacity to differentiate; however, they can (a) engraft producing experimental tumors, (b) recapitulate the tumor origin, immunophenotypically and morphologically, in xenografts, and (c) be serially transplanted. These properties apply to different type of tumors, including the solids [99].

Until the end of the 20th century, the classification of brain tumors was based largely on their histogenesis, but in recent decades an integrated classification that includes genetic analysis has been introduced [100]. The current classification of tumors describes them as: diffuse astrocytic and oligodendroglial, ependymal, choroid plexus, neuronal and mixed neuronal-glial, pineal region, histiocytic, embryonal, of the cranial and spinal nerves, meningiomas, mesenchymal, nonmeningothelial, melanocytic, lymphomas, germ cell, and of the sellar region [101].

The most common malignant tumors of the CNS are gliomas and include astrocytomas, oligodendrogliomas, ependymomas, and a variety of rare histologies [100].

\subsection{Glioblastoma}

The glioblastomas (GBMs) are the most common brain tumors (they comprise astrocytomas, oligodendrogliomas, ependymomas). The grade IV astrocytoma, is the most aggressive and common brain tumor, with an incidence of 3.2 per 100,000 and more than $15 \%$ of all primary brain tumors and $45 \%$ of malignant primary brain tumors [101]. With 18 months of average survival rate (even with an aggressive therapeutical approach), this tumor represents the most life-threatening brain tumor according to World Health Organization (WHO) figures. The malignancy of this tumor is mostly due to the high occurrence of relapse, cell infiltration and rapid invasion, and they can be classified on the basis of different gene expression patterns in the classical, neural, proneural, and mesenchymal subtypes [102]. "The Cancer Genome Atlas (TCGA)" made it possible to begin a molecular analysis of the genetic causes of GBMs. More than 140 mutated genes were found in GBMs, including tumor protein p53 (TP53), phosphatase and tensin homolog (PTEN), platelet-derived growth factor receptor $\alpha$ polypeptide (PDGFR $\alpha)$, epidermal growth factor receptor (EGFR), phosphoinositide-3-kinase catalytic alpha (PIK3CA), phosphoinositide-3-kinase regulatory 1 (PIK3R1), neurofibromin 1 (NF1), $\alpha$-thalassemia/mental retardation syndrome X-linked (ATRX), isocitrate dehydrogenase 1 (IDH1), leucine-zipper-like transcriptional regulator 1 (LZTR1), retinoblastoma 1 (RB1), and tyrosineprotein phosphatase non-receptor type 11 (PTPN11) which are the most frequently altered genes in GBMs (primary and recurrent) [90, 103-105]. Some genes are expressed only in recurrent GBMs: insulin-like growth factor 1 receptor (IGF1R), PR domain containing 2 (PRDM2), latent TGF- $\beta$ binding protein 4 (LTBP4), and MutS homolog 6 (MSH6) [105], Neurofilament Light (NEFL), and GammaAminobutyric Acid Type A Receptor Alphal Subunit (GABRA1) [106].

PTEN loss in chromosome 10 and EGFR gain in chromosome 7 are present in the classical form of GBMs; loss of NF1, gain of TNF- $\alpha$ and the high presence of TNF- $\alpha$ and mesenchymal markers such as mesenchymal-epithelial transition (MET) are indicator of the mesenchymal subtype; proneural GBMs is characterized by point mutations in IDH 1 and 2 and gains in PDGFR $\alpha$; the neural subtype (this, though, is controversial) is characterized by the expression of NEFL, GABRA1, and others [106].

Knowledge of the genetic alterations underlying of GBMs has a potential impact on the therapeutic approaches that could be used in the future (hopefully soon) for the treatments of these tumors; indeed, a comparison of the survival of the patients showed that alteration in EGFR but also in some cyclins such as cyclin-dependent kinase 4 (CDK4) and CDK inhibitor 2A (CDKN2A) are more present in patients with poorer prognosis [90]. Moreover, in GBMs are present not only direct changes in DNA sequence in many but also epigenetic modifications. These alterations, 
which include chromatin histone modifications (SUMOylation, phosphorylation, ubiquitination, and acetylation), DNA methylation, and non-coding RNAs, exert a pivotal function in gene regulation during cell development. Defects in epigenetic changes have been involved in human illness [107] including the development and progression of brain tumor [108-110].

More than $80 \%$ of secondary GBMs but only $5 \%$ of primary GBMs have IDH mutations, which are recognized as a better prognostic subgroup within GBMs patients. Slightly less than $50 \%$ of GBMs show both an EGFR gene amplification, and a splice variant [111]. IDH mutational status is at the cutting edge of the new classification for gliomas, and for glioblastomas, which are now re-classified as IDH-mutant or IDH-wildtype [112]. 90\% of the GBMs arise rapidly de novo in elderly patients and they are considered primary tumors. Secondary GBMs progress from a lower grade of diffuse or anaplastic astrocytoma and they are present mainly in younger patients, and luckily they have a significantly better prognosis. Primary and secondary GBMs are very similar in terms of histological characteristics, but their epigenetic and genetic profiles are different. IDH mutations, for instance, are present in secondary GBM [113].

\subsection{Role of GSLs in tumors}

Modifications of cell-surface sialylated structures are associated with cancer cell metastatic potential and invasiveness, and with a poor prognosis [114]. Overexpression of $b$ series gangliosides has been reported in a variety of neuro-ectoderm-derived cancers $[115,116]$. In particular GD3 and GD2 are overexpressed in tumors of the CNS, including astrocytomas, meningiomas, medulloblastomas, and neuroblastomas [117-119], whereas GD1b, GT1b, and GQ1b are less expressed in neuroblastoma tumors with respect to the normal brain and are correlated with an aggressive phenotype and a limited prognosis [120, 121]. Ganglioside antigens on the tumor cell surface, or released into the surroundings as microvesicles [122], act as an immunosuppressor and protect the tumor against the host immune system $[123,124]$. This action may be caused by the prevention of the interaction between IL-2 and its receptor and consequently the inhibition of $\mathrm{T}$ cell proliferation [125]. Furthermore, GD2 and GD3 gangliosides can induce T cell death by stimulating their production of IL10 [126], by interaction with CD70 and CD27, or by inhibition of NF-KB nuclear localization in dendritic cells $[126,127]$. GD1a prevents expression of stimulatory molecules such as CD80 and CD40 on the APC surface and decreases the production of cytokines such as IL6, IL12, and TNF- $\alpha$ [128].

Other gangliosides such as mono-sialoganglioside GM3, appear to have an opposite effect, inhibiting angiogenesis via changes to the vascular endothelial growth factor (VEGF) receptors. Brain cancers expressing elevated levels of GM3 are normally less vascularized and grow more slowly than those that express low levels of GM3 [129]. Moreover, GM3, GM1, GD1a, and GT1b inhibit proliferation of human neuroblastoma cells through the inhibition of EGFR phosphorylation [130].

It seems clear that the interplay between the molecular mechanisms of gangliosides and brain tumor carcinogenesis needs further clarification. This is particularly important in the view of the fact that cancer therapy currently includes the targeting of GD3 and GD2.

\section{Microglia-tumor interaction}

In gliomas, glioma-infiltrated microglia can be implicated in the promotion of tumor development by their stimulating the immunosuppressive microenvironment and by their invasiveness [131]. For instance, the infiltrating microglia in GBM represents $30-50 \%$ of the tumor mass. It has been hypothesized that microglia do not contrast tumor cells but rather that they help cancer cells to invade the neighboring tissue [132]. Some authors have observed a colocalization of tumor-associated microglia/macrophages (TAM/Ms) and CD133- positive glioma stem-like cells $\left(\mathrm{CD} 133^{+}\right.$GSLCs) in the marginal area of human glioma samples [133].

The capacity to evade the immune cells by generating an immunosuppressive microenvironment is the most important trademark of gliomas, in particular, GBMs [134]. This microenvironment can be built by the production of many immunosuppressive cytokines by cancer cells, namely TGF$\beta$, interleukins (IL)-6, IL-10, and prostaglandin E2 (PGE2), or by basic fibroblast growth factor (bFGF) and IL-1 and/or by inhibiting T-cell responses. All these factors trigger the immune cells to activate a tumor-supportive phenotypes such as M2 [134]. Microglia help the glioma by secreting antiinflammatory and pro-tumor factors, especially in GBMs [134]. The capacity to shift between the pro-inflammatory to the anti-inflammatory makes the microglia a key element for the physio-pathological status of the CNS $[46,131]$.

The recruitment and anti-inflammatory activation of microglia to M2 phenotype has been shown to be mediated by various chemoattractants produced by glioma cells, namely monocyte chemoattractant protein 1 (MCP-1), Stromal cell-derived factor (SDF-1), Macrophage colonystimulating factor (M-CSF), Granulocyte-macrophage colony-stimulating factor (GM-CSF), and EGF, the inhibition of these ligands or their receptors could represent a therapeutic targets $[135,136]$.

The observation that microglia were able to induce an increase in the migratory capacity of glioma cells by the release of chemoattractants in the medium [137] indicates that the resident immune cells of the CNS also exert an important role in the invasiveness of the tumor. The effect of microglia on cancer progression, however, is also directed in the maintenance of a permissive microenvironment increasing the vascularization by secreting high levels of VEGF [138]. Finally, the immunosuppressive status of the tumor microenvironment that is achieved by the release of soluble factors and by the cell-cell interaction is also a very important aspect of the interaction between tumor and microglia.

\subsection{Microglia and SLs activation in brain tumor}

The richness of SLs in CNS suggests the hypothesis that these molecules play a primary role in brain functions. Indeed, their implication in various neurological diseases has already been demonstrated: more than 30 years ago, for instance, it was suggested that lower levels of lipids in the brain and an alteration of their metabolism were related to 
Alzheimer disease, and these results were confirmed a few years ago [139]. At the present, SLs are believed to play a major role in many CNS diseases [140] including those related to inflammatory conditions [141, 142].

One of the first pieces of evidence of the activating role of SLs on microglia was reported about 20 years ago. Gangliosides can induce the production of NO and TNF- $\alpha$ and expression of cyclooxygenase-2 (COX-2) [143]. The authors also showed that the activation was dose-dependent and that different types of gangliosides indicated a differential efficacy. For instance, GT1b affected the synthesis of NO and TNF- $\alpha$ and expression of COX-2, whereas GM1 and GD1a increased the levels of COX-2 with little impact on NO and TNF- $\alpha$ release. These actions seem to be related to the activation of gangliosides via the stimulation of mitogen-activated protein kinase (MAPKs) and NF-kB [143].

The role of gangliosides in many cellular functions implies that they also play an important role in neuronal diseases. Gangliosides modify the expression of Toll-like

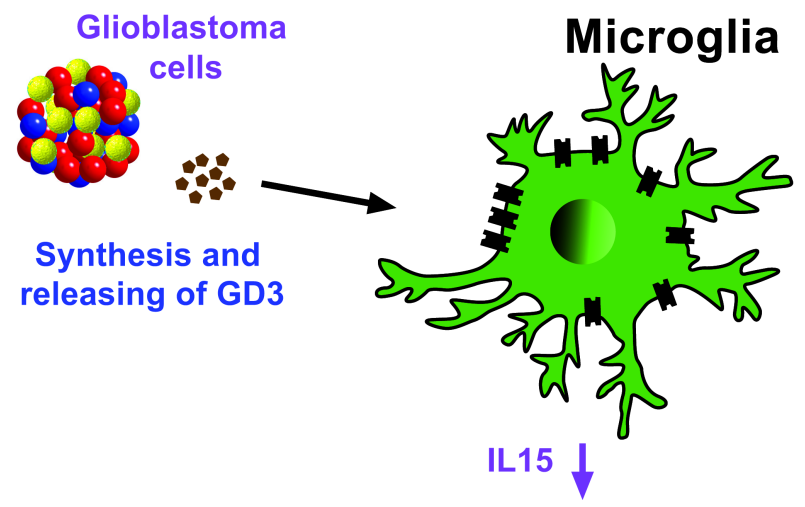

Reduced anti-inflammatory action of microglia high level of GD2 expression and release a higher GD3 amount in the medium than normal NSCs [148]. The high level of blood GD2 concentration in neuroblastoma patients is related to tumor progression and a short survival outcomes [149]. It was also found that gangliosides, including GD1a, GD1b, GD3, and GM3, enable cancer cell to evade the immune system within the tumor microenvironment [150]. In in vivo experiments, tumor-derived GM1b were able to inhibit the development of anti-tumor immune responses [151].

GD3 seems, very interestingly, to exert anti-inflammatory properties, inhibiting IL-15 [152]. In microglia cultures, treatment with GD3 reduced the levels of IL-15, causing a down-regulation of $\mathrm{NO}$ production by microglia with no effects on cell viability. On the other hand, GD3 binds to IL-15, decreasing T-cell proliferation [152]. A recent work [153] explored this concept by using microglia-glioma cocultures, and the most impressive result was that IL-15 reduced tumor size in glioma-transplanted animals. Moreover, the microglia and infiltrating monocytes, isolated from the brains of glioma-bearing mice and treated with IL-15, showed a shift of phenotype towards the proinflammatory state, with a significantly increased expression of pro-inflammatory genes and reduced expression of anti-

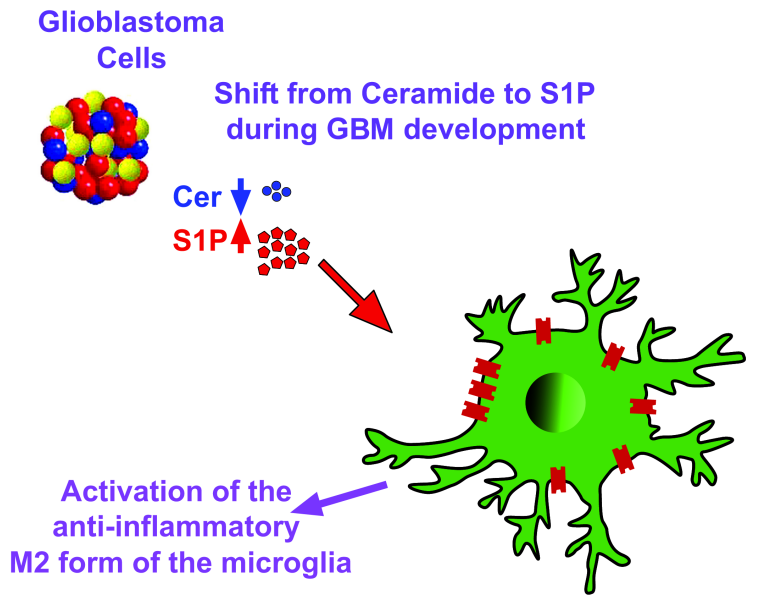

Fig. (8). Microglia activation by means of S1P interaction with S1P receptors. The shift in production of $\mathrm{Cer} / \mathrm{S} 1 \mathrm{P}$ is indicated. The latter is responsible of microglia activation to the antiinflammatory M2 form. Abbreviations: ceramide: Cer; sphingosine-1-phosphate: S1PM, glioblastoma: GBM.

inflammatory genes [153].

Taking all this information together, we can hypothesize that the glioma cells can produce GD3 and release it in the milieu, influencing the surrounding cells: including microglia. Microglia respond by reducing the levels of IL-15, which determines a down-regulation of NO and cause an anti-inflammatory action Fig. (7).

Cer, the central sphingolipid metabolite, plays a pivotal role in bringing about of cell death induced by different agents such as chemotherapeutics, radiotherapy or pro- 
apoptotic TNF- $\alpha$ family ligands [154]. Ceramidase can catabolize Cer, producing Sph which is transformed into the soluble sphingosine 1-phosphate (S1P) by SPHK1 or SPHK2. In contrast to Cer, S1P is a strong proliferative, promigratory, and pro-survival factor [155] which is secreted by GBM cells during hypoxia [156].

In most cases, S1P exerts its function by activating $\mathrm{G}$ protein-coupled receptors named S1PR1-5. S1PR1, S1PR2, and S1PR3 enhances GBM cells invasiveness in vitro [157] or bind to and modify the activity of histone deacetylases [155]. S1PR1-5 are also highly expressed in activated microglia [158].

It has already been demonstrated in different diseases that Cer plays a pro-inflammatory role in, for instance, airway inflammation, pulmonary edema, inflammatory bowel disease, inflammation during labor, post myocardium ischemic and cystic fibrosis [159-168]. But, the role of SLs in microglia was depicted only a few years ago when Jung and colleagues [162] showed that Cer with acyl chain length $\mathrm{C} 2$ to $\mathrm{C} 8$ was able to block the inflammation induced by LPS. This study showed for the first time the antiinflammatory effect of Cers in microglial activation in vitro and in vivo. Concerning the molecular mechanisms of this anti-inflammatory effect, the authors demonstrated that $\mathrm{C} 2$ Cer inhibited NF- $\mathrm{kB}, \mathrm{AP}-1$, and many signaling molecules such as PI3K/Akt, MAPKs, and Jak1/STAT1- all of which are also involved in inflammation- and that the role of $\mathrm{C} 2-$ Cer is the inhibition of NADPH oxidase activity. It seems that these actions are exerted throughout the interaction with TLR4 of microglia cells (BV2) [162].

On the other hand, it can be hypothesized that during GBMs development there is a shift of production from Cer to S1P which activate the anti-inflammatory status of microglia by means of S1P R, and thus the progression of the tumor Fig. (8).

\section{Conclusions}

Although the role of SLs as modulators in the interaction between microglia and brain tumors is still a matter of intense study, the importance of these molecules begun to be clear. It is possible that they will be important targets for therapeutical intervention in the near future.

\section{LIST OF ABBREVIATIONS}

Sphingolipids. SLs; sphingosine: Sph; glycosphingolipids: GSLs; ceramide: Cer; Ceramide transfer protein: CERT; ceramide-1-phosphate: Cer1P; sphingomyelines: SMs; N-acethylglucosamine: GlcNAc; $\mathrm{N}$-acetylgalactosamine: GalNAc; serine palmitoyltransferase: SPT; 3-keto-Dihydrosphingosine: KDS; 3-keto-dihydrosphingosine reductase: KDSR; dihydrosphingosine: dhSPH, Ceramide Synthase: CerS; dihydro ceramide: dhCer; (dihydro) ceramide desaturase: DES; sphingosine-1-phosphate: S1P; dhSphingosine-1phosphate: dhS1P; sphingosine kinase 1: SPHK1; sphingosine kinase 2: SPHK2; ceramide kinase: CerK; ceramide-1P Cer-1P; ceramide-1P: phosphatase: C1PP; sphingomyelin synthase $1 / 2$ : SMS1/2; galactosylceramide: GalCer; glucosylceramide: GluCer; glucosylceramide synthase: GluCer; glucosylceramide GluCer; acid- $\beta$ glucosylceramidase: acid- $\beta-G l u C e r a s e$; galactosylceramide synthase: GalCerS ; galactosylceramide ceramidase: GalCer ceramidase; lactosylceramide: LacCer; ganglioside: G; ganglioside M3: GM3; ganglioside D3: GD3; ganglioside D2: GD2; globotriaosylceramide 3: Gb3; acid sphingomyelinases: aSMase; sphingosine-1-phosphate phosphatases: S1PP; sphingosine-1-phosphate lyase: S1PL; ceramide-1phosphate transfer protein: CPTP; Polypeptide NAcetylgalactosaminyltransferase 1: GalNAc-T1; polypeptide N- Acetylgalactosaminyltransferase 4: GalT4; ST3 $\beta$-Galactoside Alpha-2,3-Sialyltransferase 2: ST3Gal II; ST8 Alpha-N-Acetyl-Neuraminide Alpha-2,8Sialyltransferase 5: ST $8 \mathrm{Sia}$ V; ST6 NAcetylgalactosaminide Alpha-2,6-Sialyltransferase 5: ST6GalNAc V; ST3 Beta-Galactoside Alpha-2,3Sialyltransferase 5: ST3Gal V; ST8 Alpha-N-AcetylNeuraminide Alpha-2,8-Sialyltransferase 1: ST8Sia I tumor necrosis factor: TNF- $\alpha$; Transforming growth factor- $\beta$ : TGF- $\beta$; blood brain barrier: BBB; interleukin 4 : IL-4; interleukin 13: IL-13; interleukin 15: IL-15; MAF BZIP Transcription Factor B: MafB; Myocyte Enhancer Factor 2C: Mef2C; Methyl-CpG Binding Protein 2: MeCP2; C-X3-C Motif Chemokine Receptor 1:CX3CR1; C-X3-C Motif Chemokine Ligand 1: CX3CL1; CD200 Molecule: CD200; nitric oxide: NO; inositol triphosphate: IP3; ATP binding cassette: ABC; sialyltransferases: ST; central nervous system: CNS; sub-ventricular zone: SVZ; neural stem cells: NSCs; interleukin: IL; neurotrophin-3: NT3; brain-derived neurotrophic factor: BDNF; nerve growth factor: NGF; $\gamma$-aminobutyric acid: GABA; fractalkine receptor: CX3CR1; fractalkine receptor ligand: CX3CL1; (CX3CR1); lineage-determining transcription factors: LDTF; signal-dependent transcription factors; SDTFs; interferon regulatory factors: IRF; lipopolysaccharides: LPS; amyotrophic lateral sclerosis: ALS; non-steroid nuclear receptors : liver X receptors: LXRs; retinoid X receptors: RXRs; primary malignant brain tumors: PMBTs; glioblastomas: GBMs; The Cancer Genome Atlas: TCGA; tumor protein p53: TP53; phosphatase and tensin homolog: PTEN; platelet-derived growth factor receptor $\alpha$ polypeptide: PDGFR $\alpha$; epidermal growth factor receptor: EGFR; phosphoinositide-3-kinase catalytic alpha: PIK3CA; phosphoinositide-3-kinase regulatory 1: PIK3R1; neurofibromin 1: NF1; $\alpha-$ thalassemia/mental retardation syndrome X-linked: ATRX; isocitrate dehydrogenase 1: IDH1; leucine-zipper-like transcriptional regulator 1: LZTR1; retinoblastoma 1: RB1; tyrosine-protein phosphatase non-receptor type 11:PTPN11; insulin-like growth factor 1 receptor: IGF1R; PR domain containing 2:PRDM2; latent TGF- $\beta$-binding protein 4:LTBP4; and MutS homolog 6 (MSH6); Neurofilament Light (NEFL); a $\gamma$-aminobutyric acid type A receptor $\alpha 1$ subunit: GABRA1; cyclin-dependent kinase 4: CDK4; CDK inhibitor 2A: CDKN2A; tumor-associated microglia/macrophages: TAM/Ms; prostaglandin E2: PGE2; basic fibroblast growth factor: bFGF; monocyte chemoattractant protein 1: MCP-1; stromal cell-derived factor: SDF-1; macrophage colony-stimulating factor: $\mathrm{M}$ CSF; granulocyte-macrophage colony-stimulating factor:GM-CSF; cyclooxygenase-2: COX-2; mitogenactivated protein kinase: MAPKs; Toll-like receptor 4: 
TLR4; Protein kinase c $\zeta$ : PKC $\zeta$; lipopolysaccharide: LPS. Phospholipase A2: CPLA $_{2}$; Coenzyme A: CoA; CoA synthase: CoA S; D A G: diacylglycerol; phosphatidylcholine: PC, aldehyde dehydrogenase: ALDH; four-phosphate adaptor protein 2: FAPP2; glucocerebrosidase: GCase; endoplasmic reticulum: ER.

\section{CONFLICT OF INTEREST}

The Authors declare no conflicts of interests

\section{ACKNOWLEDGEMENTS}

The authors would like to thank: Asamsi ONLUS via Prosciutta, 23-48018 Faenza (RA), Italy and Vertical Foundation, via Carlo Bernari 13, 00139 Roma (IT), Italy (BD). We would like to thank Damian Randle's proofreading and editorial service for the academic world and for business in the United Kingdom and Europe (http://englishedituk.co.uk) for the complete revision of the manuscript.

\section{REFERENCES}

[1] Thudichum, J.L.W. A Treatise on the Chemical Constituents of the Brain (a fascimile edition of the original). Bailliere, London, 1962.

[2] Merrill, A.H., Jr.; Sullards, M.C. Opinion article on lipidomics: Inherent challenges of lipidomic analysis of sphingolipids. Biochim Biophys Acta, 2017, 1862(8), 774-776.

[3] Fahy, E.; Subramaniam, S.; Brown, H.A.; Glass, C.K.; Merrill, A.H., Jr.; Murphy, R.C.; Raetz, C.R.; Russell, D.W.; Seyama, Y.; Shaw, W.; Shimizu, T.; Spener, F.; van Meer, G.; VanNieuwenhze, M.S.; White, S.H.; Witztum, J.L.; Dennis, E.A. A comprehensive classification system for lipids. J Lipid Res, 2005, 46(5), 839-861.

[4] Hannun, Y.A.; Obeid, L.M. Sphingolipids and their metabolism in physiology and disease. Nat Rev Mol Cell Biol, 2018, 19(3), 175-191.

[5] Lahiri, S.; Futerman, A.H. The metabolism and function of sphingolipids and glycosphingolipids. Cell Mol Life Sci, 2007, 64(17), 2270-2284.

[6] Gault, C.R.; Obeid, L.M.; Hannun, Y.A. An overview of sphingolipid metabolism: from synthesis to breakdown. Adv Exp Med Biol, 2010, 688, 1-23.

[7] Groux-Degroote, S.; Guerardel, Y.; Delannoy, P. Gangliosides: Structures, Biosynthesis, Analysis, and Roles in Cancer. Chembiochem, 2017, 18(13), 1146-1154.

[8] Huwiler, A.; Kolter, T.; Pfeilschifter, J.; Sandhoff, K. Physiology and pathophysiology of sphingolipid metabolism and signaling. Biochim Biophys Acta, 2000, 1485(2-3), 63-99.

[9] Futerman, A.H.; Riezman, H. The ins and outs of sphingolipid synthesis. Trends Cell Biol, 2005, 15(6), 312-318.

[10] Tettamanti, G.; Bassi, R.; Viani, P.; Riboni, L. Salvage pathways in glycosphingolipid metabolism. Biochimie, 2003, 85(3-4), 423-437.

[11] Maceyka, M.; Spiegel, S. Sphingolipid metabolites in inflammatory disease. Nature, 2014, 510(7503), 58-67.
[12] Yamaji, T.; Hanada, K. Sphingolipid metabolism and interorganellar transport: localization of sphingolipid enzymes and lipid transfer proteins. Traffic, 2015, 16(2), 101-122.

[13] Kitatani, K.; Idkowiak-Baldys, J.; Hannun, Y.A. The sphingolipid salvage pathway in ceramide metabolism and signaling. Cell Signal, 2008, 20(6), 1010-1018.

[14] Yuyama, K.; Sun, H.; Mitsutake, S.; Igarashi, Y. Sphingolipid-modulated exosome secretion promotes clearance of amyloid-beta by microglia. J Biol Chem, 2012, 287(14), 10977-10989.

[15] Zhang, H.; Desai, N.N.; Olivera, A.; Seki, T.; Brooker, G.; Spiegel, S. Sphingosine-1-phosphate, a novel lipid, involved in cellular proliferation. J Cell Biol, 1991, 114(1), 155-167.

[16] Obeid, L.M.; Linardic, C.M.; Karolak, L.A.; Hannun, Y.A. Programmed cell death induced by ceramide. Science, 1993, 259(5102), 1769-1771.

[17] Hagen, N.; Hans, M.; Hartmann, D.; Swandulla, D.; van Echten-Deckert, G. Sphingosine-1-phosphate links glycosphingolipid metabolism to neurodegeneration via a calpain-mediated mechanism. Cell Death Differ, 2011, 18(8), 1356-1365.

[18] Hahn, C.; Tyka, K.; Saba, J.D.; Lenzen, S.; GurgulConvey, E. Overexpression of sphingosine-1-phosphate lyase protects insulin-secreting cells against cytokine toxicity. $J$ Biol Chem, 2017, 292(49), 20292-20304.

[19] Mathias, S.; Kolesnick, R. Ceramide: a novel second messenger. Adv Lipid Res, 1993, 25, 65-90.

[20] Siskind, L.J.; Kolesnick, R.N.; Colombini, M. Ceramide channels increase the permeability of the mitochondrial outer membrane to small proteins. $J$ Biol Chem, 2002, 277(30), 26796-26803.

[21] Gulbins, E. Regulation of death receptor signaling and apoptosis by ceramide. Pharmacol Res, 2003, 47(5), 393-399.

[22] Chipuk, J.E.; McStay, G.P.; Bharti, A.; Kuwana, T.; Clarke, C.J.; Siskind, L.J.; Obeid, L.M.; Green, D.R. Sphingolipid metabolism cooperates with BAK and BAX to promote the mitochondrial pathway of apoptosis. Cell, 2012, 148(5), 988-1000.

[23] Saddoughi, S.A.; Ogretmen, B. Diverse functions of ceramide in cancer cell death and proliferation. Adv Cancer Res, 2013, 117, 37-58.

[24] Sentelle, R.D.; Senkal, C.E.; Jiang, W.; Ponnusamy, S.; Gencer, S.; Selvam, S.P.; Ramshesh, V.K.; Peterson, Y.K.; Lemasters, J.J.; Szulc, Z.M.; Bielawski, J.; Ogretmen, B. Ceramide targets autophagosomes to mitochondria and induces lethal mitophagy. Nat Chem Biol, 2012, 8(10), 831-838.

[25] Salazar, M.; Carracedo, A.; Salanueva, I.J.; Hernandez-Tiedra, S.; Lorente, M.; Egia, A.; Vazquez, P.; Blazquez, C.; Torres, S.; Garcia, S.; Nowak, J.; Fimia, G.M.; Piacentini, M.; Cecconi, F.; Pandolfi, P.P.; Gonzalez-Feria, L.; Iovanna, J.L.; Guzman, M.; Boya, P.; Velasco, G. Cannabinoid action induces autophagy-mediated cell death through stimulation of ER stress in human glioma cells. $J$ Clin Invest, 2009, 119(5), 1359-1372.

[26] Ogretmen, B. Sphingolipid metabolism in cancer signalling and therapy. Nat Rev Cancer, 2018, 18(1), 33-50. 
[27] Parham, K.A.; Zebol, J.R.; Tooley, K.L.; Sun, W.Y.; Moldenhauer, L.M.; Cockshell, M.P.; Gliddon, B.L.; Moretti, P.A.; Tigyi, G.; Pitson, S.M.; Bonder, C.S. Sphingosine 1phosphate is a ligand for peroxisome proliferator-activated receptor-gamma that regulates neoangiogenesis. FASEB J, 2015, 29(9), 3638-3653.

[28] Chalfant, C.E.; Spiegel, S. Sphingosine 1-phosphate and ceramide 1-phosphate: expanding roles in cell signaling. $J$ Cell Sci, 2005, 118(Pt 20), 4605-4612.

[29] Boujaoude, L.C.; Bradshaw-Wilder, C.; Mao, C.; Cohn, J.; Ogretmen, B.; Hannun, Y.A.; Obeid, L.M. Cystic fibrosis transmembrane regulator regulates uptake of sphingoid base phosphates and lysophosphatidic acid: modulation of cellular activity of sphingosine 1-phosphate. $J$ Biol Chem, 2001, 276(38), 35258-35264.

[30] Mitra, P.; Oskeritzian, C.A.; Payne, S.G.; Beaven, M.A.; Milstien, S.; Spiegel, S. Role of ABCC1 in export of sphingosine-1-phosphate from mast cells. Proc Natl Acad Sci US A, 2006, 103(44), 16394-16399.

[31] Fu, P.; Ebenezer, D.L.; Ha, A.W.; Suryadevara, V.; Harijith, A.; Natarajan, V. Nuclear Lipid Mediators: Role of Nuclear Sphingolipids and Sphinosine-1-Phosphate Signaling in Epigenetic Regulation of Inflammation and Gene Expression. J Cell Biochem, 2018.

[32] Zeng, G.; Yu, R.K. Cloning and transcriptional regulation of genes responsible for synthesis of gangliosides. Curr Drug Targets, 2008, 9(4), 317-324.

[33] van Echten-Deckert, G.; Herget, T. Sphingolipid metabolism in neural cells. Biochim Biophys Acta, 2006, 1758(12), 1978-1994.

[34] Bottai, D.; Adami, R.; Ghidoni, R. The crosstalk between glycosphingolipids and neural stem cells. $J$ Neurochem, 2018.

[35] Sierra, A.; de Castro, F.; Del Rio-Hortega, J.; Rafael Iglesias-Rozas, J.; Garrosa, M.; Kettenmann, H. The "BigBang" for modern glial biology: Translation and comments on Pio del Rio-Hortega 1919 series of papers on microglia. Glia, 2016, 64(11), 1801-1840.

[36] Ginhoux, F.; Greter, M.; Leboeuf, M.; Nandi, S.; See, P.; Gokhan, S.; Mehler, M.F.; Conway, S.J.; Ng, L.G.; Stanley, E.R.; Samokhvalov, I.M.; Merad, M. Fate mapping analysis reveals that adult microglia derive from primitive macrophages. Science, 2010, 330(6005), 841-845.

[37] Gomez Perdiguero, E.; Klapproth, K.; Schulz, C.; Busch, K.; Azzoni, E.; Crozet, L.; Garner, H.; Trouillet, C.; de Bruijn, M.F.; Geissmann, F.; Rodewald, H.R. Tissueresident macrophages originate from yolk-sac-derived erythro-myeloid progenitors. Nature, 2015, 518(7540), 547-551.

[38] Iturri, L.; Saenz Coronilla, J.; Lallemand, Y.; Gomez Perdiguero, E. Identification Of Erythromyeloid Progenitors And Their Progeny In The Mouse Embryo By Flow Cytometry. $J$ Vis Exp, 2017(125).

[39] Kierdorf, K.; Prinz, M. Microglia in steady state. $J$ Clin Invest, 2017, 127(9), 3201-3209.

[40] Badie, B.; Schartner, J.M. Flow cytometric characterization of tumor-associated macrophages in experimental gliomas. Neurosurgery, 2000, 46(4), 957-961; discussion 961-952.
[41] Hanisch, U.K.; Kettenmann, H. Microglia: active sensor and versatile effector cells in the normal and pathologic brain. Nat Neurosci, 2007, 10(11), 1387-1394.

[42] Gomez-Nicola, D.; Valle-Argos, B.; Pita-Thomas, D.W.; Nieto-Sampedro, M. Interleukin 15 expression in the CNS: blockade of its activity prevents glial activation after an inflammatory injury. Glia, 2008, 56(5), 494-505.

[43] Gomez-Nicola, D.; Valle-Argos, B.; NietoSampedro, M. Blockade of IL-15 activity inhibits microglial activation through the NFkappaB, p38, and ERK1/2 pathways, reducing cytokine and chemokine release. Glia, 2010, 58(3), 264-276.

[44] Lisi, L.; Stigliano, E.; Lauriola, L.; Navarra, P.; Dello Russo, C. Proinflammatory-activated glioma cells induce a switch in microglial polarization and activation status, from a predominant M $2 \mathrm{~b}$ phenotype to a mixture of M1 and M2a/B polarized cells. ASN Neuro, 2014, 6(3), 171-183.

[45] Ginhoux, F.; Prinz, M. Origin of microglia: current concepts and past controversies. Cold Spring Harb Perspect Biol, 2015, 7(8), a020537.

[46] Hambardzumyan, D.; Gutmann, D.H.; Kettenmann, $\mathrm{H}$. The role of microglia and macrophages in glioma maintenance and progression. Nat Neurosci, 2016, 19(1), 20-27.

[47] Dekkers, M.P.; Barde, Y.A. Developmental biology. Programmed cell death in neuronal development. Science, 2013, 340(6128), 39-41.

[48] Dekkers, M.P.; Nikoletopoulou, V.; Barde, Y.A. Cell biology in neuroscience: Death of developing neurons: new insights and implications for connectivity. J Cell Biol, 2013, 203(3), 385-393.

[49] Ashwell, K. Microglia and cell death in the developing mouse cerebellum. Brain Res Dev Brain Res, 1990, 55(2), 219-230.

[50] Witting, A.; Muller, P.; Herrmann, A.; Kettenmann, H.; Nolte, C. Phagocytic clearance of apoptotic neurons by Microglia/Brain macrophages in vitro: involvement of lectin-, integrin-, and phosphatidylserine-mediated recognition. J Neurochem, 2000, 75(3), 1060-1070.

[51] Marin-Teva, J.L.; Dusart, I.; Colin, C.; Gervais, A.; van Rooijen, N.; Mallat, M. Microglia promote the death of developing Purkinje cells. Neuron, 2004, 41(4), 535-547.

[52] Ueno, M.; Fujita, Y.; Tanaka, T.; Nakamura, Y.; Kikuta, J.; Ishii, M.; Yamashita, T. Layer V cortical neurons require microglial support for survival during postnatal development. Nat Neurosci, 2013, 16(5), 543-551.

[53] Bottai, D.; Fiocco, R.; Gelain, F.; Defilippis, L.; Galli, R.; Gritti, A.; Vescovi, L.A. Neural stem cells in the adult nervous system. J Hematother Stem Cell Res, 2003, 12(6), 655-670.

[54] Adami, R.; Pagano, J.; Colombo, M.; Platonova, N.; Recchia, D.; Chiaramonte, R.; Bottinelli, R.; Canepari, M.; Bottai, D. Reduction of Movement in Neurological Diseases: Effects on Neural Stem Cells Characteristics. Front Neurosci, 2018, 12, 336.

[55] Cunningham, C.L.; Martinez-Cerdeno, V.; Noctor, S.C. Microglia regulate the number of neural precursor cells in the developing cerebral cortex. J Neurosci, 2013, 33(10), 4216-4233. 
[56] Lawson, L.J.; Perry, V.H.; Dri, P.; Gordon, S. Heterogeneity in the distribution and morphology of microglia in the normal adult mouse brain. Neuroscience, 1990, 39(1), 151-170.

[57] Abiega, O.; Beccari, S.; Diaz-Aparicio, I.; Nadjar, A.; Laye, S.; Leyrolle, Q.; Gomez-Nicola, D.; Domercq, M.; Perez-Samartin, A.; Sanchez-Zafra, V.; Paris, I.; Valero, J.; Savage, J.C.; Hui, C.W.; Tremblay, M.E.; Deudero, J.J.; Brewster, A.L.; Anderson, A.E.; Zaldumbide, L.; Galbarriatu, L.; Marinas, A.; Vivanco, M.; Matute, C.; Maletic-Savatic, M.; Encinas, J.M.; Sierra, A. Neuronal Hyperactivity Disturbs ATP Microgradients, Impairs Microglial Motility, and Reduces Phagocytic Receptor Expression Triggering Apoptosis/Microglial Phagocytosis Uncoupling. PLoS Biol, 2016, 14(5), e1002466.

[58] Sierra, A.; Encinas, J.M.; Deudero, J.J.; Chancey, J.H.; Enikolopov, G.; Overstreet-Wadiche, L.S.; Tsirka, S.E.; Maletic-Savatic, M. Microglia shape adult hippocampal neurogenesis through apoptosis-coupled phagocytosis. Cell Stem Cell, 2010, 7(4), 483-495.

[59] Gertig, U.; Hanisch, U.K. Microglial diversity by responses and responders. Front Cell Neurosci, 2014, 8, 101. [60] Gadani, S.P.; Smirnov, I.; Smith, A.T.; Overall, C.C.; Kipnis, J. Characterization of meningeal type 2 innate lymphocytes and their response to CNS injury. J Exp Med, 2017, 214(2), 285-296.

[61] Butovsky, O.; Jedrychowski, M.P.; Moore, C.S.; Cialic, R.; Lanser, A.J.; Gabriely, G.; Koeglsperger, T.; Dake, B.; Wu, P.M.; Doykan, C.E.; Fanek, Z.; Liu, L.; Chen, Z.; Rothstein, J.D.; Ransohoff, R.M.; Gygi, S.P.; Antel, J.P.; Weiner, H.L. Identification of a unique TGF-beta-dependent molecular and functional signature in microglia. Nat Neurosci, 2014, 17(1), 131-143.

[62] Shin, W.H.; Lee, D.Y.; Park, K.W.; Kim, S.U.; Yang, M.S.; Joe, E.H.; Jin, B.K. Microglia expressing interleukin-13 undergo cell death and contribute to neuronal survival in vivo. Glia, 2004, 46(2), 142-152.

[63] Zhao, X.; Wang, H.; Sun, G.; Zhang, J.; Edwards, N.J.; Aronowski, J. Neuronal Interleukin-4 as a Modulator of Microglial Pathways and Ischemic Brain Damage. $J$ Neurosci, 2015, 35(32), 11281-11291.

[64] Neumann, H.; Misgeld, T.; Matsumuro, K.; Wekerle, H. Neurotrophins inhibit major histocompatibility class II inducibility of microglia: involvement of the p75 neurotrophin receptor. Proc Natl Acad Sci US A, 1998, 95(10), 5779-5784.

[65] Lee, M. Neurotransmitters and microglial-mediated neuroinflammation. Curr Protein Pept Sci, 2013, 14(1), 21-32.

[66] Neumann, H.; Boucraut, J.; Hahnel, C.; Misgeld, T.; Wekerle, H. Neuronal control of MHC class II inducibility in rat astrocytes and microglia. Eur $J$ Neurosci, 1996, 8(12), 2582-2590.

[67] Harrison, J.K.; Jiang, Y.; Chen, S.; Xia, Y.; Maciejewski, D.; McNamara, R.K.; Streit, W.J.; Salafranca, M.N.; Adhikari, S.; Thompson, D.A.; Botti, P.; Bacon, K.B.; Feng, L. Role for neuronally derived fractalkine in mediating interactions between neurons and CX3CR1-expressing microglia. Proc Natl Acad Sci US A, 1998, 95(18), 10896-10901.
[68] Cohen, M.; Ben-Yehuda, H.; Porat, Z.; Raposo, C.; Gordon, S.; Schwartz, M. Newly Formed Endothelial Cells Regulate Myeloid Cell Activity Following Spinal Cord Injury via Expression of CD200 Ligand. J Neurosci, 2017, 37(4), 972-985.

[69] Cronk, J.C.; Derecki, N.C.; Ji, E.; Xu, Y.; Lampano, A.E.; Smirnov, I.; Baker, W.; Norris, G.T.; Marin, I.; Coddington, N.; Wolf, Y.; Turner, S.D.; Aderem, A.; Klibanov, A.L.; Harris, T.H.; Jung, S.; Litvak, V.; Kipnis, J. Methyl-CpG Binding Protein 2 Regulates Microglia and Macrophage Gene Expression in Response to Inflammatory Stimuli. Immunity, 2015, 42(4), 679-691.

[70] Matcovitch-Natan, O.; Winter, D.R.; Giladi, A.; Vargas Aguilar, S.; Spinrad, A.; Sarrazin, S.; Ben-Yehuda, H.; David, E.; Zelada Gonzalez, F.; Perrin, P.; Keren-Shaul, H.; Gury, M.; Lara-Astaiso, D.; Thaiss, C.A.; Cohen, M.; Bahar Halpern, K.; Baruch, K.; Deczkowska, A.; LorenzoVivas, E.; Itzkovitz, S.; Elinav, E.; Sieweke, M.H.; Schwartz, M.; Amit, I. Microglia development follows a stepwise program to regulate brain homeostasis. Science, 2016, 353(6301), aad8670.

[71] Nerlov, C.; Graf, T. PU.1 induces myeloid lineage commitment in multipotent hematopoietic progenitors. Genes Dev, 1998, 12(15), 2403-2412.

[72] Koso, H.; Tsuhako, A.; Lai, C.Y.; Baba, Y.; Otsu, M.; Ueno, K.; Nagasaki, M.; Suzuki, Y.; Watanabe, S. Conditional rod photoreceptor ablation reveals Sall1 as a microglial marker and regulator of microglial morphology in the retina. Glia, 2016, 64(11), 2005-2024.

[73] Cuevas, V.D.; Anta, L.; Samaniego, R.; OrtaZavalza, E.; Vladimir de la Rosa, J.; Baujat, G.; DominguezSoto, A.; Sanchez-Mateos, P.; Escribese, M.M.; Castrillo, A.; Cormier-Daire, V.; Vega, M.A.; Corbi, A.L. MAFB Determines Human Macrophage Anti-Inflammatory Polarization: Relevance for the Pathogenic Mechanisms Operating in Multicentric Carpotarsal Osteolysis. J Immunol, 2017, 198(5), 2070-2081.

[74] Lanzillotta, A.; Porrini, V.; Bellucci, A.; Benarese, M.; Branca, C.; Parrella, E.; Spano, P.F.; Pizzi, M. NFkappaB in Innate Neuroprotection and Age-Related Neurodegenerative Diseases. Front Neurol, 2015, 6, 98.

[75] Rivas-Arancibia, S.; Zimbron, L.F.; RodriguezMartinez, E.; Maldonado, P.D.; Borgonio Perez, G.; Sepulveda-Parada, M. Oxidative stress-dependent changes in immune responses and cell death in the substantia nigra after ozone exposure in rat. Front Aging Neurosci, 2015, 7, 65.

[76] Wang, Z.; Liu, D.; Wang, F.; Liu, S.; Zhao, S.; Ling, E.A.; Hao, A. Saturated fatty acids activate microglia via Toll-like receptor 4/NF-kappaB signalling. Br J Nutr, 2012, 107(2), 229-241.

[77] Kaminska, B.; Mota, M.; Pizzi, M. Signal transduction and epigenetic mechanisms in the control of microglia activation during neuroinflammation. Biochim Biophys Acta, 2016, 1862(3), 339-351.

[78] Kierdorf, K.; Erny, D.; Goldmann, T.; Sander, V.; Schulz, C.; Perdiguero, E.G.; Wieghofer, P.; Heinrich, A.; Riemke, P.; Holscher, C.; Muller, D.N.; Luckow, B.; Brocker, T.; Debowski, K.; Fritz, G.; Opdenakker, G.; Diefenbach, A.; Biber, K.; Heikenwalder, M.; Geissmann, F.; Rosenbauer, F.; Prinz, M. Microglia emerge from 
erythromyeloid precursors via $\mathrm{Pu} .1$ - and Irf8-dependent pathways. Nat Neurosci, 2013, 16(3), 273-280.

[79] Masuda, T.; Nishimoto, N.; Tomiyama, D.; Matsuda, T.; Tozaki-Saitoh, H.; Tamura, T.; Kohsaka, S.; Tsuda, M.; Inoue, K. IRF8 is a transcriptional determinant for microglial motility. Purinergic Signal, 2014, 10(3), 515-521.

[80] Aloi, M.S.; Su, W.; Garden, G.A. The p53 Transcriptional Network Influences Microglia Behavior and Neuroinflammation. Crit Rev Immunol, 2015, 35(5), 401-415.

[81] Abdjul, D.B.; Yamazaki, H.; Kanno, S.I.; Tomizawa, A.; Rotinsulu, H.; Wewengkang, D.S.; Sumilat, D.A.; Ukai, K.; Kapojos, M.M.; Namikoshi, M. An antimycobacterial bisfunctionalized sphingolipid and new bromopyrrole alkaloid from the Indonesian marine sponge Agelas sp. J Nat Med, 2017, 71(3), 531-536.

[82] Yu, Z.; Sun, D.; Feng, J.; Tan, W.; Fang, X.; Zhao, M.; Zhao, X.; Pu, Y.; Huang, A.; Xiang, Z.; Cao, L.; He, C. MSX3 Switches Microglia Polarization and Protects from Inflammation-Induced Demyelination. $J$ Neurosci, 2015, 35(16), 6350-6365.

[83] Saijo, K.; Winner, B.; Carson, C.T.; Collier, J.G.; Boyer, L.; Rosenfeld, M.G.; Gage, F.H.; Glass, C.K. A Nurr1/CoREST pathway in microglia and astrocytes protects dopaminergic neurons from inflammation-induced death. Cell, 2009, 137(1), 47-59.

[84] Bruce-Keller, A.J.; Keeling, J.L.; Keller, J.N.; Huang, F.F.; Camondola, S.; Mattson, M.P. Antiinflammatory effects of estrogen on microglial activation. Endocrinology, 2000, 141(10), 3646-3656.

[85] Yamanaka, M.; Ishikawa, T.; Griep, A.; Axt, D.; Kummer, M.P.; Heneka, M.T. PPARgamma/RXRalphainduced and CD36-mediated microglial amyloid-beta phagocytosis results in cognitive improvement in amyloid precursor protein/presenilin 1 mice. J Neurosci, 2012, 32(48), 17321-17331.

[86] Savage, J.C.; Jay, T.; Goduni, E.; Quigley, C.; Mariani, M.M.; Malm, T.; Ransohoff, R.M.; Lamb, B.T.; Landreth, G.E. Nuclear receptors license phagocytosis by trem $2+$ myeloid cells in mouse models of Alzheimer's disease. J Neurosci, 2015, 35(16), 6532-6543.

[87] Parsons, D.W.; Jones, S.; Zhang, X.; Lin, J.C.; Leary, R.J.; Angenendt, P.; Mankoo, P.; Carter, H.; Siu, I.M.; Gallia, G.L.; Olivi, A.; McLendon, R.; Rasheed, B.A.; Keir, S.; Nikolskaya, T.; Nikolsky, Y.; Busam, D.A.; Tekleab, H.; Diaz, L.A., Jr.; Hartigan, J.; Smith, D.R.; Strausberg, R.L.; Marie, S.K.; Shinjo, S.M.; Yan, H.; Riggins, G.J.; Bigner, D.D.; Karchin, R.; Papadopoulos, N.; Parmigiani, G.; Vogelstein, B.; Velculescu, V.E.; Kinzler, K.W. An integrated genomic analysis of human glioblastoma multiforme. Science, 2008, 321(5897), 1807-1812.

[88] Parsons, D.W.; Li, M.; Zhang, X.; Jones, S.; Leary, R.J.; Lin, J.C.; Boca, S.M.; Carter, H.; Samayoa, J.; Bettegowda, C.; Gallia, G.L.; Jallo, G.I.; Binder, Z.A.; Nikolsky, Y.; Hartigan, J.; Smith, D.R.; Gerhard, D.S.; Fults, D.W.; VandenBerg, S.; Berger, M.S.; Marie, S.K.; Shinjo, S.M.; Clara, C.; Phillips, P.C.; Minturn, J.E.; Biegel, J.A.; Judkins, A.R.; Resnick, A.C.; Storm, P.B.; Curran, T.; He, Y.; Rasheed, B.A.; Friedman, H.S.; Keir, S.T.; McLendon, R.; Northcott, P.A.; Taylor, M.D.; Burger, P.C.; Riggins, G.J.;
Karchin, R.; Parmigiani, G.; Bigner, D.D.; Yan, H.; Papadopoulos, N.; Vogelstein, B.; Kinzler, K.W.; Velculescu, V.E. The genetic landscape of the childhood cancer medulloblastoma. Science, 2011, 331(6016), 435-439.

[89] Bettegowda, C.; Agrawal, N.; Jiao, Y.; Wang, Y.; Wood, L.D.; Rodriguez, F.J.; Hruban, R.H.; Gallia, G.L.; Binder, Z.A.; Riggins, C.J.; Salmasi, V.; Riggins, G.J.; Reitman, Z.J.; Rasheed, A.; Keir, S.; Shinjo, S.; Marie, S.; McLendon, R.; Jallo, G.; Vogelstein, B.; Bigner, D.; Yan, H.; Kinzler, K.W.; Papadopoulos, N. Exomic sequencing of four rare central nervous system tumor types. Oncotarget, 2013, $4(4), 572-583$.

[90] Brennan, C.W.; Verhaak, R.G.; McKenna, A.; Campos, B.; Noushmehr, H.; Salama, S.R.; Zheng, S.; Chakravarty, D.; Sanborn, J.Z.; Berman, S.H.; Beroukhim, R.; Bernard, B.; Wu, C.J.; Genovese, G.; Shmulevich, I.; Barnholtz-Sloan, J.; Zou, L.; Vegesna, R.; Shukla, S.A.; Ciriello, G.; Yung, W.K.; Zhang, W.; Sougnez, C.; Mikkelsen, T.; Aldape, K.; Bigner, D.D.; Van Meir, E.G.; Prados, M.; Sloan, A.; Black, K.L.; Eschbacher, J.; Finocchiaro, G.; Friedman, W.; Andrews, D.W.; Guha, A.; Iacocca, M.; O'Neill, B.P.; Foltz, G.; Myers, J.; Weisenberger, D.J.; Penny, R.; Kucherlapati, R.; Perou, C.M.; Hayes, D.N.; Gibbs, R.; Marra, M.; Mills, G.B.; Lander, E.; Spellman, P.; Wilson, R.; Sander, C.; Weinstein, J.; Meyerson, M.; Gabriel, S.; Laird, P.W.; Haussler, D.; Getz, G.; Chin, L.; Network, T.R. The somatic genomic landscape of glioblastoma. Cell, 2013, 155(2), 462-477.

[91] Dubuc, A.M.; Remke, M.; Korshunov, A.; Northcott, P.A.; Zhan, S.H.; Mendez-Lago, M.; Kool, M.; Jones, D.T.; Unterberger, A.; Morrissy, A.S.; Shih, D.; Peacock, J.; Ramaswamy, V.; Rolider, A.; Wang, X.; Witt, H.; Hielscher, T.; Hawkins, C.; Vibhakar, R.; Croul, S.; Rutka, J.T.; Weiss, W.A.; Jones, S.J.; Eberhart, C.G.; Marra, M.A.; Pfister, S.M.; Taylor, M.D. Aberrant patterns of H3K4 and H3K27 histone lysine methylation occur across subgroups in medulloblastoma. Acta Neuropathol, 2013, 125(3), 373-384.

[92] Mack, S.C.; Witt, H.; Piro, R.M.; Gu, L.; Zuyderduyn, S.; Stutz, A.M.; Wang, X.; Gallo, M.; Garzia, L.; Zayne, K.; Zhang, X.; Ramaswamy, V.; Jager, N.; Jones, D.T.; Sill, M.; Pugh, T.J.; Ryzhova, M.; Wani, K.M.; Shih, D.J.; Head, R.; Remke, M.; Bailey, S.D.; Zichner, T.; Faria, C.C.; Barszczyk, M.; Stark, S.; Seker-Cin, H.; Hutter, S.; Johann, P.; Bender, S.; Hovestadt, V.; Tzaridis, T.; Dubuc, A.M.; Northcott, P.A.; Peacock, J.; Bertrand, K.C.; Agnihotri, S.; Cavalli, F.M.; Clarke, I.; Nethery-Brokx, K.; Creasy, C.L.; Verma, S.K.; Koster, J.; Wu, X.; Yao, Y.; Milde, T.; Sin-Chan, P.; Zuccaro, J.; Lau, L.; Pereira, S.; Castelo-Branco, P.; Hirst, M.; Marra, M.A.; Roberts, S.S.; Fults, D.; Massimi, L.; Cho, Y.J.; Van Meter, T.; Grajkowska, W.; Lach, B.; Kulozik, A.E.; von Deimling, A.; Witt, O.; Scherer, S.W.; Fan, X.; Muraszko, K.M.; Kool, M.; Pomeroy, S.L.; Gupta, N.; Phillips, J.; Huang, A.; Tabori, U.; Hawkins, C.; Malkin, D.; Kongkham, P.N.; Weiss, W.A.; Jabado, N.; Rutka, J.T.; Bouffet, E.; Korbel, J.O.; Lupien, M.; Aldape, K.D.; Bader, G.D.; Eils, R.; Lichter, P.; Dirks, P.B.; Pfister, S.M.; Korshunov, A.; Taylor, M.D. Epigenomic alterations define lethal CIMP-positive ependymomas of infancy. Nature, 2014, 506(7489), 445-450. 
[93] Calabrese, C.; Poppleton, H.; Kocak, M.; Hogg, T.L.; Fuller, C.; Hamner, B.; Oh, E.Y.; Gaber, M.W.; Finklestein, D.; Allen, M.; Frank, A.; Bayazitov, I.T.; Zakharenko, S.S.; Gajjar, A.; Davidoff, A.; Gilbertson, R.J. A perivascular niche for brain tumor stem cells. Cancer Cell, 2007, 11(1), 69-82.

[94] Slongo, M.L.; Molena, B.; Brunati, A.M.; Frasson, M.; Gardiman, M.; Carli, M.; Perilongo, G.; Rosolen, A.; Onisto, M. Functional VEGF and VEGF receptors are expressed in human medulloblastomas. Neuro Oncol, 2007, 9(4), 384-392.

[95] de Robles, P.; Fiest, K.M.; Frolkis, A.D.; Pringsheim, T.; Atta, C.; St Germaine-Smith, C.; Day, L.; Lam, D.; Jette, N. The worldwide incidence and prevalence of primary brain tumors: a systematic review and metaanalysis. Neuro Oncol, 2015, 17(6), 776-783.

[96] Arvold, N.D.; Lee, E.Q.; Mehta, M.P.; Margolin, K.; Alexander, B.M.; Lin, N.U.; Anders, C.K.; Soffietti, R.; Camidge, D.R.; Vogelbaum, M.A.; Dunn, I.F.; Wen, P.Y. Updates in the management of brain metastases. Neuro Oncol, 2016, 18(8), 1043-1065.

[97] Nayak, L.; Lee, E.Q.; Wen, P.Y. Epidemiology of brain metastases. Curr Oncol Rep, 2012, 14(1), 48-54.

[98] Vescovi, A.L.; Galli, R.; Reynolds, B.A. Brain tumour stem cells. Nat Rev Cancer, 2006, 6(6), 425-436.

[99] Park, C.Y.; Tseng, D.; Weissman, I.L. Cancer stem cell-directed therapies: recent data from the laboratory and clinic. Mol Ther, 2009, 17(2), 219-230.

[100] Louis, D.N.; Perry, A.; Reifenberger, G.; von Deimling, A.; Figarella-Branger, D.; Cavenee, W.K.; Ohgaki, H.; Wiestler, O.D.; Kleihues, P.; Ellison, D.W. The 2016 World Health Organization Classification of Tumors of the Central Nervous System: a summary. Acta Neuropathol, 2016, 131(6), 803-820.

[101] McFaline-Figueroa, J.R.; Lee, E.Q. Brain Tumors. Am J Med, 2018.

[102] Cai, X.; Sughrue, M.E. Glioblastoma: new therapeutic strategies to address cellular and genomic complexity. Oncotarget, 2018, 9(10), 9540-9554.

[103] Cancer Genome Atlas Research, Network. Comprehensive genomic characterization defines human glioblastoma genes and core pathways. Nature, 2008, 455(7216), 1061-1068.

[104] Frattini, V.; Trifonov, V.; Chan, J.M.; Castano, A.; Lia, M.; Abate, F.; Keir, S.T.; Ji, A.X.; Zoppoli, P.; Niola, F.; Danussi, C.; Dolgalev, I.; Porrati, P.; Pellegatta, S.; Heguy, A.; Gupta, G.; Pisapia, D.J.; Canoll, P.; Bruce, J.N.; McLendon, R.E.; Yan, H.; Aldape, K.; Finocchiaro, G.; Mikkelsen, T.; Prive, G.G.; Bigner, D.D.; Lasorella, A.; Rabadan, R.; Iavarone, A. The integrated landscape of driver genomic alterations in glioblastoma. Nat Genet, 2013, 45(10), 1141-1149.

[105] Wang, J.; Cazzato, E.; Ladewig, E.; Frattini, V.; Rosenbloom, D.I.; Zairis, S.; Abate, F.; Liu, Z.; Elliott, O.; Shin, Y.J.; Lee, J.K.; Lee, I.H.; Park, W.Y.; Eoli, M.; Blumberg, A.J.; Lasorella, A.; Nam, D.H.; Finocchiaro, G.; Iavarone, A.; Rabadan, R. Clonal evolution of glioblastoma under therapy. Nat Genet, 2016, 48(7), 768-776.

[106] Verhaak, R.G.; Hoadley, K.A.; Purdom, E.; Wang, V.; Qi, Y.; Wilkerson, M.D.; Miller, C.R.; Ding, L.; Golub, T.; Mesirov, J.P.; Alexe, G.; Lawrence, M.; O'Kelly, M.;
Tamayo, P.; Weir, B.A.; Gabriel, S.; Winckler, W.; Gupta, S.; Jakkula, L.; Feiler, H.S.; Hodgson, J.G.; James, C.D.; Sarkaria, J.N.; Brennan, C.; Kahn, A.; Spellman, P.T.; Wilson, R.K.; Speed, T.P.; Gray, J.W.; Meyerson, M.; Getz, G.; Perou, C.M.; Hayes, D.N.; Cancer Genome Atlas Research, N. Integrated genomic analysis identifies clinically relevant subtypes of glioblastoma characterized by abnormalities in PDGFRA, IDH1, EGFR, and NF1. Cancer Cell, 2010, 17(1), 98-110.

[107] Portela, A.; Esteller, M. Epigenetic modifications and human disease. Nat Biotechnol, 2010, 28(10), 1057-1068.

[108] Mack, S.C.; Hubert, C.G.; Miller, T.E.; Taylor, M.D.; Rich, J.N. An epigenetic gateway to brain tumor cell identity. Nat Neurosci, 2016, 19(1), 10-19.

[109] Lee, D.H.; Ryu, H.W.; Won, H.R.; Kwon, S.H. Advances in epigenetic glioblastoma therapy. Oncotarget, 2017, 8(11), 18577-18589.

[110] Zhang, Y.; Cruickshanks, N.; Pahuski, M.; Yuan, F.; Dutta, A.; Schiff, D.; Purow, B.; Abounader, R. In Glioblastoma. De Vleeschouwer, S., Ed.: Brisbane (AU), 2017.

[111] Aldape, K.; Zadeh, G.; Mansouri, S.; Reifenberger, G.; von Deimling, A. Glioblastoma: pathology, molecular mechanisms and markers. Acta Neuropathol, 2015, 129(6), 829-848.

[112] Sanson, M.; Marie, Y.; Paris, S.; Idbaih, A.; Laffaire, J.; Ducray, F.; El Hallani, S.; Boisselier, B.; Mokhtari, K.; Hoang-Xuan, K.; Delattre, J.Y. Isocitrate dehydrogenase 1 codon 132 mutation is an important prognostic biomarker in gliomas. J Clin Oncol, 2009, 27(25), 4150-4154

[113] Ohgaki, H.; Kleihues, P. The definition of primary and secondary glioblastoma. Clin Cancer Res, 2013, 19(4), 764-772.

[114] Krengel, U.; Bousquet, P.A. Molecular recognition of gangliosides and their potential for cancer immunotherapies. Front Immunol, 2014, 5, 325.

[115] Furukawa, K.; Hamamura, K.; Aixinjueluo, W.; Furukawa, K. Biosignals modulated by tumor-associated carbohydrate antigens: novel targets for cancer therapy. Ann N Y Acad Sci, 2006, 1086, 185-198.

[116] Daniotti, J.L.; Vilcaes, A.A.; Torres Demichelis, V.; Ruggiero, F.M.; Rodriguez-Walker, M. Glycosylation of glycolipids in cancer: basis for development of novel therapeutic approaches. Front Oncol, 2013, 3, 306.

[117] Berra, B.; Gaini, S.M.; Riboni, L. Correlation between ganglioside distribution and histological grading of human astrocytomas. Int J Cancer, 1985, 36(3), 363-366.

[118] Zeng, G.; Li, D.D.; Gao, L.; Birkle, S.; Bieberich, E.; Tokuda, A.; Yu, R.K. Alteration of ganglioside composition by stable transfection with antisense vectors against GD3-synthase gene expression. Biochemistry, 1999, 38(27), 8762-8769.

[119] Zeng, G.; Gao, L.; Birkle, S.; Yu, R.K. Suppression of ganglioside GD3 expression in a rat F-11 tumor cell line reduces tumor growth, angiogenesis, and vascular endothelial growth factor production. Cancer Res, 2000, 60(23), 6670-6676.

[120] Hettmer, S.; Malott, C.; Woods, W.; Ladisch, S.; Kaucic, K. Biological stratification of human neuroblastoma 
by complex "B" pathway ganglioside expression. Cancer Res, 2003, 63(21), 7270-7276.

[121] Hettmer, S.; Ladisch, S.; Kaucic, K. Low complex ganglioside expression characterizes human neuroblastoma cell lines. Cancer Lett, 2005, 225(1), 141-149.

[122] Li, C.C.; Eaton, S.A.; Young, P.E.; Lee, M.; Shuttleworth, R.; Humphreys, D.T.; Grau, G.E.; Combes, V.; Bebawy, M.; Gong, J.; Brammah, S.; Buckland, M.E.; Suter, C.M. Glioma microvesicles carry selectively packaged coding and non-coding RNAs which alter gene expression in recipient cells. RNA Biol, 2013, 10(8), 1333-1344.

[123] Dyatlovitskaya, E.V.; Kandyba, A.G. Role of biologically active sphingolipids in tumor growth. Biochemistry (Mosc), 2006, 71(1), 10-17.

[124] Dyatlovitskaya, E.V.; Kandyba, A.G. Sphingolipids in tumor metastases and angiogenesis. Biochemistry (Mosc), 2006, 71(4), 347-353.

[125] Birkle, S.; Zeng, G.; Gao, L.; Yu, R.K.; Aubry, J. Role of tumor-associated gangliosides in cancer progression. Biochimie, 2003, 85(3-4), 455-463.

[126] Caldwell, S.; Heitger, A.; Shen, W.; Liu, Y.; Taylor, B.; Ladisch, S. Mechanisms of ganglioside inhibition of APC function. J Immunol, 2003, 171(4), 1676-1683.

[127] Fukumoto, S.; Mutoh, T.; Hasegawa, T.; Miyazaki, H.; Okada, M.; Goto, G.; Furukawa, K.; Urano, T. GD3 synthase gene expression in PC12 cells results in the continuous activation of TrkA and ERK1/2 and enhanced proliferation. $J$ Biol Chem, 2000, 275(8), 5832-5838.

[128] Bull, C.; den Brok, M.H.; Adema, G.J. Sweet escape: sialic acids in tumor immune evasion. Biochim Biophys Acta, 2014, 1846(1), 238-246.

[129] Seyfried, T.N.; Mukherjee, P. Ganglioside GM3 Is Antiangiogenic in Malignant Brain Cancer. $J$ Oncol, 2010, $2010,961243$.

[130] Mirkin, B.L.; Clark, S.H.; Zhang, C. Inhibition of human neuroblastoma cell proliferation and EGF receptor phosphorylation by gangliosides GM1, GM3, GD1A and GT1B. Cell Prolif, 2002, 35(2), 105-115.

[131] da Fonseca, A.C.; Amaral, R.; Garcia, C.; Geraldo, L.H.; Matias, D.; Lima, F.R. Microglia in Cancer: For Good or for Bad? Adv Exp Med Biol, 2016, 949, 245-261.

[132] Roggendorf, W.; Strupp, S.; Paulus, W. Distribution and characterization of microglia/macrophages in human brain tumors. Acta Neuropathol, 1996, 92(3), 288-293.

[133] Ye, X.Z.; Xu, S.L.; Xin, Y.H.; Yu, S.C.; Ping, Y.F.; Chen, L.; Xiao, H.L.; Wang, B.; Yi, L.; Wang, Q.L.; Jiang, X.F.; Yang, L.; Zhang, P.; Qian, C.; Cui, Y.H.; Zhang, X.; Bian, X.W. Tumor-associated microglia/macrophages enhance the invasion of glioma stem-like cells via TGFbeta1 signaling pathway. J Immunol, 2012, 189(1), 444-453. [134] Matias, D.; Predes, D.; Niemeyer Filho, P.; Lopes, M.C.; Abreu, J.G.; Lima, F.R.S.; Moura Neto, V. Microgliaglioblastoma interactions: New role for Wnt signaling. Biochim Biophys Acta, 2017, 1868(1), 333-340.

[135] Komohara, Y.; Ohnishi, K.; Kuratsu, J.; Takeya, M. Possible involvement of the M2 anti-inflammatory macrophage phenotype in growth of human gliomas. $J$ Pathol, 2008, 216(1), 15-24.

[136] Roesch, S.; Rapp, C.; Dettling, S.; Herold-Mende, C. When Immune Cells Turn Bad-Tumor-Associated
Microglia/Macrophages in Glioma. Int $J$ Mol Sci, 2018, $19(2)$.

[137] Bettinger, I.; Thanos, S.; Paulus, W. Microglia promote glioma migration. Acta Neuropathol, 2002, 103(4), 351-355.

[138] Brandenburg, S.; Muller, A.; Turkowski, K.; Radev, Y.T.; Rot, S.; Schmidt, C.; Bungert, A.D.; Acker, G.; Schorr, A.; Hippe, A.; Miller, K.; Heppner, F.L.; Homey, B.; Vajkoczy, P. Resident microglia rather than peripheral macrophages promote vascularization in brain tumors and are source of alternative pro-angiogenic factors. Acta Neuropathol, 2016, 131(3), 365-378.

[139] van Echten-Deckert, G.; Walter, J. Sphingolipids: critical players in Alzheimer's disease. Prog Lipid Res, 2012, 51(4), 378-393.

[140] Jana, A.; Hogan, E.L.; Pahan, K. Ceramide and neurodegeneration: susceptibility of neurons and oligodendrocytes to cell damage and death. J Neurol Sci, 2009, 278(1-2), 5-15.

[141] El Alwani, M.; Wu, B.X.; Obeid, L.M.; Hannun, Y.A. Bioactive sphingolipids in the modulation of the inflammatory response. Pharmacol Ther, 2006, 112(1), 171-183.

[142] Haughey, N.J. Sphingolipids in neurodegeneration. Neuromolecular Med, 2010, 12(4), 301-305.

[143] Pyo, H.; Joe, E.; Jung, S.; Lee, S.H.; Jou, I. Gangliosides activate cultured rat brain microglia. $J$ Biol Chem, 1999, 274(49), 34584-34589.

[144] Jou, I.; Lee, J.H.; Park, S.Y.; Yoon, H.J.; Joe, E.H.; Park, E.J. Gangliosides trigger inflammatory responses via TLR4 in brain glia. Am J Pathol, 2006, 168(5), 1619-1630.

[145] Bieberich, E. Ceramide signaling in cancer and stem cells. Future Lipidol, 2008, 3(3), 273-300.

[146] Wikstrand, C.J.; Fredman, P.; McLendon, R.R.; Svennerholm, L.; Bigner, D.D. Altered expression of ganglioside phenotypes of human gliomas in vivo and in vitro. Mol Chem Neuropathol, 1994, 21(2-3), 129-138.

[147] Wikstrand, C.J.; Fredman, P.; Svennerholm, L.; Bigner, D.D. Detection of glioma-associated gangliosides GM2, GD2, GD3, 3'-isoLM1 3',6'-isoLD1 in central nervous system tumors in vitro and in vivo using epitope-defined monoclonal antibodies. Prog Brain Res, 1994, 101, 213-223.

[148] Yeh, S.C.; Wang, P.Y.; Lou, Y.W.; Khoo, K.H.; Hsiao, M.; Hsu, T.L.; Wong, C.H. Glycolipid GD3 and GD3 synthase are key drivers for glioblastoma stem cells and tumorigenicity. Proc Natl Acad Sci U S A, 2016, 113(20), 5592-5597.

[149] Valentino, L.; Moss, T.; Olson, E.; Wang, H.J.; Elashoff, R.; Ladisch, S. Shed tumor gangliosides and progression of human neuroblastoma. Blood, 1990, 75(7), 1564-1567.

[150] Potapenko, M.; Shurin, G.V.; de Leon, J. Gangliosides as immunomodulators. Adv Exp Med Biol, 2007, 601, 195-203.

[151] McKallip, R.; Li, R.; Ladisch, S. Tumor gangliosides inhibit the tumor-specific immune response. $J$ Immunol, 1999, 163(7), 3718-3726.

[152] Gomez-Nicola, D.; Doncel-Perez, E.; NietoSampedro, M. Regulation by GD3 of the proinflammatory response of microglia mediated by interleukin-15. J Neurosci Res, 2006, 83(5), 754-762. 
[153] Garofalo, S.; Porzia, A.; Mainiero, F.; Di Angelantonio, S.; Cortese, B.; Basilico, B.; Pagani, F.; Cignitti, G.; Chece, G.; Maggio, R.; Tremblay, M.E.; Savage, J.; Bisht, K.; Esposito, V.; Bernardini, G.; Seyfried, T.; Mieczkowski, J.; Stepniak, K.; Kaminska, B.; Santoni, A.; Limatola, C. Environmental stimuli shape microglial plasticity in glioma. Elife, 2017, 6 .

[154] Hannun, Y.A.; Obeid, L.M. Principles of bioactive lipid signalling: lessons from sphingolipids. Nat Rev Mol Cell Biol, 2008, 9(2), 139-150.

[155] Maceyka, M.; Harikumar, K.B.; Milstien, S.; Spiegel, S. Sphingosine-1-phosphate signaling and its role in disease. Trends Cell Biol, 2012, 22(1), 50-60.

[156] Anelli, V.; Gault, C.R.; Cheng, A.B.; Obeid, L.M. Sphingosine kinase 1 is up-regulated during hypoxia in U87MG glioma cells. Role of hypoxia-inducible factors 1 and 2. J Biol Chem, 2008, 283(6), 3365-3375.

[157] Young, N.; Van Brocklyn, J.R. Roles of sphingosine-1-phosphate (S1P) receptors in malignant behavior of glioma cells. Differential effects of S1P2 on cell migration and invasiveness. Exp Cell Res, 2007, 313(8), 1615-1627.

[158] Nayak, D.; Huo, Y.; Kwang, W.X.; Pushparaj, P.N.; Kumar, S.D.; Ling, E.A.; Dheen, S.T. Sphingosine kinase 1 regulates the expression of proinflammatory cytokines and nitric oxide in activated microglia. Neuroscience, 2010, 166(1), 132-144.

[159] Goggel, R.; Winoto-Morbach, S.; Vielhaber, G.; Imai, Y.; Lindner, K.; Brade, L.; Brade, H.; Ehlers, S.; Slutsky, A.S.; Schutze, S.; Gulbins, E.; Uhlig, S. PAFmediated pulmonary edema: a new role for acid sphingomyelinase and ceramide. Nat Med, 2004, 10(2), $155-160$.

[160] Masini, E.; Giannini, L.; Nistri, S.; Cinci, L.; Mastroianni, R.; Xu, W.; Comhair, S.A.; Li, D.; Cuzzocrea, S.; Matuschak, G.M.; Salvemini, D. Ceramide: a key signaling molecule in a Guinea pig model of allergic asthmatic response and airway inflammation. J Pharmacol Exp Ther, 2008, 324(2), 548-557.

[161] Teichgraber, V.; Ulrich, M.; Endlich, N.; Riethmuller, J.; Wilker, B.; De Oliveira-Munding, C.C.; van Heeckeren, A.M.; Barr, M.L.; von Kurthy, G.; Schmid, K.W.; Weller, M.; Tummler, B.; Lang, F.; Grassme, H.; Doring, G.; Gulbins, E. Ceramide accumulation mediates inflammation, cell death and infection susceptibility in cystic fibrosis. Nat Med, 2008, 14(4), 382-391.

[162] Jung, J.S.; Shin, K.O.; Lee, Y.M.; Shin, J.A.; Park, E.M.; Jeong, J.; Kim, D.H.; Choi, J.W.; Kim, H.S. Antiinflammatory mechanism of exogenous $\mathrm{C} 2$ ceramide in lipopolysaccharide-stimulated microglia. Biochim Biophys Acta, 2013, 1831(6), 1016-1026.

[163] Ghidoni, R.; Caretti, A.; Signorelli, P. Role of Sphingolipids in the Pathobiology of Lung Inflammation. Mediators Inflamm, 2015, 2015, 487508.

[164] Caretti, A.; Torelli, R.; Perdoni, F.; Falleni, M.; Tosi, D.; Zulueta, A.; Casas, J.; Sanguinetti, M.; Ghidoni, R.; Borghi, E.; Signorelli, P. Inhibition of ceramide de novo synthesis by myriocin produces the double effect of reducing pathological inflammation and exerting antifungal activity against A. fumigatus airways infection. Biochim Biophys Acta, 2016, $1860(6), 1089-1097$.
[165] Reforgiato, M.R.; Milano, G.; Fabrias, G.; Casas, J.; Gasco, P.; Paroni, R.; Samaja, M.; Ghidoni, R.; Caretti, A.; Signorelli, P. Inhibition of ceramide de novo synthesis as a postischemic strategy to reduce myocardial reperfusion injury. Basic Res Cardiol, 2016, 111(2), 12.

[166] Signorelli, P.; Avagliano, L.; Reforgiato, M.R.; Toppi, N.; Casas, J.; Fabrias, G.; Marconi, A.M.; Ghidoni, R.; Caretti, A. De novo ceramide synthesis is involved in acute inflammation during labor. Biol Chem, 2016, 397(2), 147-155.

[167] Caretti, A.; Vasso, M.; Bonezzi, F.T.; Gallina, A.; Trinchera, M.; Rossi, A.; Adami, R.; Casas, J.; Falleni, M.; Tosi, D.; Bragonzi, A.; Ghidoni, R.; Gelfi, C.; Signorelli, P. Myriocin treatment of $\mathrm{CF}$ lung infection and inflammation: complex analyses for enigmatic lipids. Naunyn Schmiedebergs Arch Pharmacol, 2017, 390(8), 775-790.

[168] Zulueta, A.; Caretti, A.; Campisi, G.M.; Brizzolari, A.; Abad, J.L.; Paroni, R.; Signorelli, P.; Ghidoni, R. Inhibitors of ceramide de novo biosynthesis rescue damages induced by cigarette smoke in airways epithelia. Naunyn Schmiedebergs Arch Pharmacol, 2017, 390(7), 753-759. 